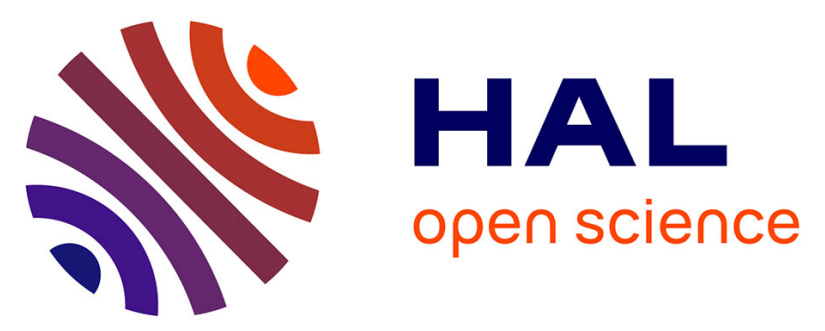

\title{
The LMDZ4 general circulation model: climate performance and sensitivity to parametrized physics with emphasis on tropical convection
}

Frédéric Hourdin, Ionela Musat, Sandrine Bony, Pascale Braconnot, Francis

Codron, Jean-Louis Dufresne, Laurent Fairhead, Marie-Angèle Filiberti,

Pierre Friedlingstein, Jean-Yves Grandpeix, et al.

\section{To cite this version:}

Frédéric Hourdin, Ionela Musat, Sandrine Bony, Pascale Braconnot, Francis Codron, et al.. The LMDZ4 general circulation model: climate performance and sensitivity to parametrized physics with emphasis on tropical convection. Climate Dynamics, 2006, 19, pp.3445-3482. 10.1007/s00382-0060158-0 . hal-00113202

\author{
HAL Id: hal-00113202 \\ https://hal.science/hal-00113202
}

Submitted on 13 Nov 2006

HAL is a multi-disciplinary open access archive for the deposit and dissemination of scientific research documents, whether they are published or not. The documents may come from teaching and research institutions in France or abroad, or from public or private research centers.
L'archive ouverte pluridisciplinaire HAL, est destinée au dépôt et à la diffusion de documents scientifiques de niveau recherche, publiés ou non, émanant des établissements d'enseignement et de recherche français ou étrangers, des laboratoires publics ou privés. 


\title{
The LMDZ4 general circulation model: climate performance and sensitivity to parametrized physics with emphasis on tropical convection
}

\author{
Frédéric Hourdin*1, Ionela Musat ${ }^{1}$, Sandrine Bony ${ }^{1}$, Pascale Braconnot ${ }^{2}$, Francis Codron ${ }^{1}$ \\ Jean-Louis Dufresne ${ }^{1}$, Laurent Fairhead ${ }^{1}$, Marie-Angèle Filiberti ${ }^{3}$, Pierre Friedlingstein ${ }^{2}$, \\ Jean-Yves Grandpeix ${ }^{1}$, Gerhard Krinner ${ }^{4}$, Phu LeVan ${ }^{1}$, Zhao-Xin Li ${ }^{1}$, François Lott ${ }^{1}$ \\ ${ }^{1}$ Laboratoire de Météorologie Dynamique, LMD/IPSL, Paris \\ ${ }^{2}$ Laboratoire des Sciences du Climat et de l'Environnement, LSCE/IPSL, Saclay \\ ${ }^{3}$ Institut Pierre Simon Laplace, IPSL, Paris \\ ${ }^{4}$ Laboratoire de Glaciologie et Géophysique de l'Environnement, Grenoble.
}

\section{Submitted to Climate Dynamics}

Submitted, May 2005, Revised, December 22, 2005

\begin{abstract}
The LMDZ4 general circulation model is the atmospheric component of the IPSL-CM4 coupled model which has been used to perform climate change simulations for the 4th IPCC assessment report. The main aspects of the model climatology (forced by observed sea surface temperature) are documented here, as well as the major improvements with respect to the previous versions, which mainly come form the parametrization of tropical convection. A systematic methodology is proposed to help analyse the sensitivity of the tropical Hadley-Walker circulation to the parametrization of cumulus convection and clouds. The tropical circulation is characterized using scalar potentials associated with the horizontal wind and horizontal transport of geopotential (the Laplacian of which is proportional to the total vertical momentum in the atmospheric column). The effect of parametrized physics is analysed in a regime sorted framework using the vertical velocity at $500 \mathrm{hPa}$ as a proxy for large scale vertical motion. Compared to Tiedtke's convection scheme, used in previous versions, the Emanuel's scheme im-
\end{abstract}

\footnotetext{
* Corresponding author address: Laboratoire de Météorologie Dynamique, UPMC, Tr 45-55, 3eme et., B99, F-75252 Paris Cedex 05, FRANCE; E-mail : hourdin@lmd.jussieu.fr; Tel : 331-44278410; Fax: 33-1-44276272
}

proves the representation of the Hadley-Walker circulation, with a relatively stronger and deeper large scale vertical ascent over tropical continents, and suppresses the marked patterns of concentrated rainfall over oceans. Thanks to the regime sorted analyses, this differences are attributed to intrinsic differences in the vertical distribution of convective heating, and to the lack of self-inhibition by precipitating downdraughts in Tiedtke's parametrization. Both the convection and cloud schemes are shown to control the relative importance of large scale convection over land and ocean, an important point for the behaviour of the coupled model.

\section{Introduction}

A great amount of effort has been spent in the past few years by climate modellers to prepare improved climate models suited to climate change simulations, in support of the 4th assessment report of the Intergovernmental Panel on Climate Change (IPCC).

Climate change modelling is a particular exercise in that the sensitivity of the model to anthropogenic forcing can hardly be assessed with respect to observation. Because of uncertainties in radiative forcing and because of climate internal variability, 
the observed 20th century climate change does not yet provide a strong constraint on climate sensitivity (Wigley et al., 1997; Gregory et al., 2005). To overcome this difficulty, one can use however the climate variations observed in the past decades or paleoclimate records in order to identify key mechanisms involved in the climate sensitivity, which may then serve as a guide for validation of the model and improvement of its physical content. A key issue in that respect is the representation of unresolved subgridscale processes accounted for in climate models through parametrizations, in which the complexity of the real world is reduced to a few deterministic equations. A full climate change prediction, for a given "scenario" of anthropogenic emissions, also requires appropriate treatment of ocean thermodynamics and circulation, water budget including routing from continental surfaces to the ocean, as well as computation of the evolution of the atmospheric composition, under the effect of bio-geochemical processes for carbon dioxide or chemistry for methane or ozone.

The general circulation model LMDZ4 presented here is the atmospheric component of the IPSL-CM4 version of the Institut Pierre Simon Laplace Coupled Model (Marti et al., 2005), developed with the above mentioned perspective in mind, and recently used to produce climate change simulations for IPCC (Dufresne et al., 2005). With respect to the previous LMDZ3 version (Li, 1999; Li and Conil, 2003), the major change in terms of physical content concerns the representation of cumulus convection, the Tiedtke (1989) scheme being replaced by the Emanuel (1991, 1993) scheme. After the development and tuning of LMDZ4, another version was derived which only differs by the use of Tiedtke's scheme in place of Emanuel's for convection. Both versions are presented here. They will be used in a companion paper to analyse the role of the parametrized convection on the coupled climate and climate sensitivity (Braconnot et al., in preparation).

Here we relate some characteristic behaviours of those very different parametrizations to the changes observed in the simulated climate and large-scale circulation. This question is generally difficult to address because the cumulus convection and largescale circulation are tightly coupled. To overcome this difficulty, we propose the following methodology: we characterize on the one hand the parametrization behaviour for a given large-scale regime using the monthly mean of the vertical velocity as a proxy for the large-scale circulation, a framework proposed by Bony et al. (1997) to analyse cloud radiative forcing and feedbacks; on the other hand, we characterize the impact of those different parametrizations on the large-scale circulation using the velocity potential as well as a z-weighted potential, the Laplacian of which corresponds approximately to the vertical momentum of atmospheric columns. Note that the main focus here is not to discuss the impact of one particular aspect of the convective parametrization such as closure, triggering or entrainment. A better strategy for that would be to vary parts of one particular convection scheme (see e. g., Jakob and Siebesma, 2003; Grandpeix et al., 2005).

Major model improvements and tunings are first presented in section 2. Then we document in section 3 some aspects of the simulated climate. Finally in section 4, we analyse in more details the sensitivity of the simulated climate to the parametrized physics with a focus on the relationships between tropical convection and divergent circulation. One goal of this paper is to serve as a reference for the analysis of the IPCC simulations, so that the model content and climatology are described in some details. For readers who would like to concentrate on the sensitivity analysis concerning the tropical convection and Hadley-Walker circulation and on methodological aspects, sections 2.3, 2.4 and 3.2 may be sufficient to introduce the core of the discussion (sections 4.3 and 4.4).

\section{Model description}

\section{$2.1 \quad$ LMDZ}

LMDZ is the second generation of a climate model developed at Laboratoire de Météorologie Dynamique (Sadourny and Laval, 1984; Le Treut et al., 1994; Le Treut et al., 1998). The dynamical equations are discretised on the sphere in a staggered and longitudelatitude Arakawa C-grid (see e. g. Kasahara, 1977). The grid is stretchable (the $\mathrm{Z}$ of LMDZ standing for Zoom capability) so that the model can be used for climate studies at both global (Li, 1999; Li and Conil, 2003) and regional scale (Krinner and Genthon, 1998; Genthon et al., 2002; Zhou and Li, 2002; Poutou et al., 2004; Krinner et al., 2004). The discretization ensures numerical conservation of both enstrophy (square of the wind rotational) for barotropic flows (following Sadourny, 1975b,a) and angular momentum for the axi-symmetric component. The finite-difference formulation thus correctly represents the enstrophy transfer from large to small scales of motions, down to grid-scale cut-off. An horizontal dissipation is added to the dynamical equations. Based on an iterated Laplacian, it is designed so as to represent properly the pumping of enstrophy at the cut-off scale. The time step is bounded by a CFL criterion on the fastest 
gravity modes. For the applications presented here, with a uniform resolution of $3.75^{\circ}$ in longitude and $2.5^{\circ}$ in latitude, the time-step is 3 minutes. For latitudes poleward of 60 degrees in both hemispheres, a longitudinal filter is applied in order to limit the effective resolution to the one at 60 degrees. The time integration is done using a leapfrog scheme, with a periodic predictor/corrector time-step. On the vertical, the model uses a classical hybrid $\sigma-p$ coordinate $^{1}$. The standard version is based on 19 layers $^{2}$ with the first 4 layers in the first kilometre above surface, a mean vertical resolution of about $2 \mathrm{~km}$ between 2 and $20 \mathrm{~km}$ and 4 layers above $20 \mathrm{~km}$.

Both vapour and liquid water are advected with a monotonic second order finite volume scheme (Van Leer, 1977; Hourdin and Armengaud, 1999). This scheme is used also for the simulation of the direct and inverse transport of trace species (Hourdin and Issartel, 2000; Krinner and Genthon, 2003; Cosme et al., 2005; Hourdin et al., 2005) and coupling with a module of atmospheric chemistry and aerosols (INCA, Hauglustaine et al., 2004).

\section{$2.2 \quad$ Parametrized physics}

Different sets of parametrized physics are coupled to the same dynamical core through a common interface, including specific versions for Mars (Hourdin et al., 1993; Forget et al., 1999; Levrard et al., 2004) and Titan (Hourdin et al., 1995; Rannou et al., 2002). The dynamical core is written in a $3 \mathrm{D}$ world whereas the physics package is coded as a juxtaposition of independent 1D columns. Thus testing the physics package in a single-column context or developing simple climate models in a latitude-altitude frame (Hourdin et al., 2004) are easily done. We describe below the parametrized physics which defines the LMDZ4 version used for the IPCC simulations (Dufresne et al., 2005).

The radiation scheme is the one introduced several years ago in the model of the European Centre for Medium-Range Weather Forecasts (ECMWF) by Morcrette: the solar part is a refined version of the scheme developed by Fouquart and Bonnel (1980) and the thermal infra-red part is due to Morcrette et al. (1986). The radiative active species are $\mathrm{H}_{2} \mathrm{O}, \mathrm{O}_{3}, \mathrm{CO}_{2}$, $\mathrm{O}_{2}, \mathrm{~N}_{2} \mathrm{O}, \mathrm{CH}_{4}, \mathrm{NO}_{2}$ and CFCs. The direct and first

\footnotetext{
${ }^{1}$ The pressure $p_{l}$ in layer $l$ is defined as a function of surface pressure $p_{s}$ as $p_{l}=A_{l} p_{s}+B_{l}$. The values of $A_{l}$ and $B_{l}$ are chosen in such a way that the $A_{l} p_{s}$ part dominates near the surface (where $A_{l}$ reaches 1 ), so that the coordinate follows the surface topography, and $B_{l}$ dominates above several $\mathrm{km}$, making the coordinate equivalent to a pressure coordinate.

${ }^{2}$ A 50-layer version is also used for stratospheric studies (Lott et al., 2005).
}

indirect radiative effects of sulfate aerosols (introduced in LMDZ according to Boucher and Pham, 2002; Quaas et al., 2004) are not activated here. The effects of mountains (drag, lift, gravity waves) are accounted for using state-of-the-art schemes (Lott and Miller, 1997; Lott, 1999). Cloud, convection and boundary layer schemes, which have been significantly modified in the last few years, are described below.

\subsection{Parametrization of moist convec- tion}

The Tiedtke's (1989) scheme, used in previous versions of LMDZ, was replaced by the Emanuel's (1991, 1993) scheme which improved significantly the large scale distribution of tropical precipitation as discussed later in the paper. Both schemes are based on a "mass flux" representation of the convective updraughts and downdraughts as well as of the induced motions in the environmental air.

In the Tiedtke's scheme, only one convective cloud is considered, comprising one single saturated updraught. Entrainment and detrainment between the cloud and the environment can take place at any level between the free convection level and the zero-buoyancy level. There is also one single downdraught extending from the free sinking level to the cloud base. The mass flux at the top of the downdraught is a constant fraction (here 0.3 ) of the convective mass flux at cloud base. This downdraught is assumed to be saturated and is kept at saturation by evaporating precipitation. The version used here is close to the original formulation of Tiedtke (1989) and relies on a closure in moisture convergence. Triggering is a function of the buoyancy of lifted parcels at the first grid level above condensation level. Most models that use the Tiedtke's scheme today have changed at least the closure, introducing the CAPE (Convective Available Potential Energy) in one way or another (see e. g. Jakob and Siebesma, 2003).

In the Emanuel's scheme, the backbone of the convective systems are regions of adiabatic ascent originating from some low-level layer and ending at their level of neutral buoyancy $(L N B)$. Shedding from these adiabatic ascents yields, at each level, a set of draughts which are mixtures of adiabatic ascent air (from which some precipitation is removed) and environmental air. These mixed draughts move adiabatically up or down to levels where, after further removal of precipitation and evaporation of cloud water, they are at rest at their new levels of neutral buoyancy. In addition to those buoyancy-sorted saturated draughts, unsaturated downdraughts are parametrized as a single entraining plume of constant 
fractional area (here $1 \%$ of the grid cell) driven by the evaporation of precipitation. The version of the Emanuel's scheme used here is close to Emanuel (1993). Closure and triggering take into account both tropospheric instability and convective inhibition. The mass flux $M_{B}$ at cloud base reads:

$$
M_{B}=\frac{\alpha}{p_{0}} \int_{p_{L N B}}^{p_{B}}\left(\frac{\max \left(B_{\min (p)}, 0\right)}{B_{0}}\right)^{2} \rho \sqrt{C A P E_{(p)}} d p
$$

where $p_{B}=p_{L C L}-40 h P a, p_{L C L}$ and $p_{L N B}$ are pressure at $L C L$ and at $L N B$ respectively, $B_{\min (p)}$ is the lower bound of adiabatically lifted parcel buoyancy between levels $p_{B}$ and $p, B_{0}=1 \mathrm{~K}$ and $p_{0}=10^{5} \mathrm{~Pa}$ are reference values for the buoyancy and pressure respectively and $C A P E_{(p)}$ is the work of buoyancy forces between levels $p_{B}$ and $p$. $\alpha=0.03$ is a scale factor. Inhibition is accounted for by the $B_{\min }$ term and tropospheric instability by the $C A P E$ term. With respect to the version released by Kerry Emanuel, most of the explicit grid dependencies have been removed (e.g. lifting condensation level $L C L$ varies continuously and not from grid level to grid level).

Emanuel's and Tiedtke's mass flux schemes thus differ by several fundamental aspects. The triggering depends on atmospheric stability in both schemes (the max in the closure formula for Emanuel's) but only the closure in Emanuel's scheme does. Also the ratio of the downdraught to updraught mass fluxes is limited for Tiedtke (0.3 at the downdraught top) but not for Emanuel (it can be occasionally greater than 1). As a matter of fact, Emanuel's scheme is one of the few schemes simulating precipitating downdraughts with an intensity comparable to the one obtained in CRM simulations (Guichard et al., 2004). Finally, the updraught in Tiedtke's parametrization is an entraining plume. Both its vertical extension and intensity are thus sensitive to the humidity of the free troposphere. In Emanuel's scheme, the adiabatic updraught does not entrain air from the free troposphere so that the cloud top is always at $L N B$. A dry free troposphere can thus reduce convection (by modifying the humidity of the mixed draughts) but not limit its vertical extension.

\subsection{Cloud scheme}

As originally proposed by Sommeria and Deardorff (1977), the cloud cover $f$ and cloud water content $q_{c}$ are diagnosed from the large scale value $\overline{q_{t}}$ of the total (vapour + condensed) water $q_{t}$, the moisture at saturation $q_{\text {sat }}$, and the subgrid scale variability of the total water, through a Probability Distribution Function (PDF). Following Bony and Emanuel (2001), the top-hat distribution used previously (Le Treut and
Li, 1991) was replaced in LMDZ4 by a generalised lognormal PDF (Hosking and Wallis, 1997) defined by three statistical moments (mean, variance, skewness). By using zero as a lower bound, the PDF depends on two parameters only (the mean $\overline{q_{t}}$ and variance $\sigma$ ) and becomes positively skewed. The skewness increases with increasing values of the ratio $r=\sigma / \overline{q_{t}}$. When this ratio is small compared to 1 , the distribution is close to a Gaussian distribution. Since $\overline{q_{t}}$ is predicted explicitly by the GCM, the only unknown to be determined is $\sigma$ (or $r$ ). The cloud cover seen by the radiative code is computed as the maximum of the so called "large scale" and "convective" cloud fractions.

For the "Large-scale clouds", $f$ and $q_{c}$ are predicted from the large scale variables $\overline{q_{t}}$ and $q_{\text {sat }}$ by imposing the parameter $r$ of the PDF. $r$ increases (as a linear function of pressure) from $r_{0}$ at the surface to $r_{1}$ at pressure $p_{1}=300 \mathrm{hPa}$. This shape was chosen rather arbitrarily and the numerical values retained for $r_{0}(=0.05)$ and $r_{1}(=0.33)$ were fixed during the tuning phase of the LMDZ4 version. Part of the condensed water is precipitated in the cloudy fraction of the grid cell. The precipitation is partially re-evaporated when falling through unsaturated atmospheric layers.

In convective regions, large-scale variables are poor predictors of the cloud fraction ( $\mathrm{Xu}$ and Randall 1996b), and the parametrization of clouds needs to be coupled to the convective parametrization. Here, these "convective clouds" are computed differently depending on the convective parametrization used.

When the Tiedtke's scheme is used, a homogeneous cloud cover between the cloud base and cloud top is imposed, its value being a function of the vertical integral of the positive part of the moisture sink due to convection. In the previous LMDZ versions, the cloud cover was predicted with the same function but applied to the total convective rainfall at the surface (Slingo, 1987). Both predictors are identical for strongly precipitating systems but the new one results in a much more realistic cloud cover in regions with non precipitating convection.

When using the Emanuel's scheme, the cloud and convective parametrizations are coupled following the approach proposed by Bony and Emanuel (2001) and evaluated in a single-column model forced by TOGA$\mathrm{COARE}^{3}$ data. In this approach, the in-cloud water content $q_{c}$ predicted by the convection scheme is used, together with $\overline{q_{t}}$ and $q_{\text {sat }}$, to infer the variance $\sigma$ (or $r$ ) of the $q_{t}$ PDF through an inverse procedure. The PDF is used afterward to predict the cloud fraction $f$ (see appendix B of Bony and Emanuel 2001).

\footnotetext{
${ }^{3}$ TOGA-COARE: Tropical Ocean Global Atmosphere Coupled Ocean-Atmosphere Response Experiment.
} 
Cloud microphysical properties are computed as described in Bony and Emanuel (2001, Table 2 for water clouds and case "ICE-OPT" of Table 3 for ice clouds): temperature thresholds $\left(-15^{\circ} \mathrm{C}\right.$ and $\left.0^{\circ} \mathrm{C}\right)$ are used to partition the cloud condensate into liquid and frozen cloud water mixing ratios; cloud optical thickness is computed by using an effective radius of cloud particles set to a constant value for liquid water clouds $(12 \mu \mathrm{m}$ in the simulations presented here), and decreasing with decreasing temperature (from 60 to $3.5 \mu \mathrm{m}$ ) for ice clouds (Suzuki et al., 1993; Heymsfield and Platt, 1984). The vertical overlap of cloud layers is assumed to be maximum-random.

\subsection{The boundary layer scheme}

The (quite old) boundary layer scheme of the LMDZ3 version was kept for LMDZ4 with some adjustments and ad-hoc tunings. The vertical turbulent transport is treated as a diffusion. Up-gradient transport of heat in the convective boundary layer is ensured by adding a prescribed counter-gradient of $-1 \mathrm{~K} \mathrm{~km}^{-1}$ to the vertical derivative of potential temperature (Deardorff, 1966). Unstable profiles are prevented using a dry convective adjustment. The surface boundary layer is treated according to Louis (1979). Over oceans, the surface roughness length is computed following Smith (1988). The ratio between the neutral drag coefficient for heat and momentum is fixed to 0.8 , consistently with the ratio obtained by Smith (1988) in moderate to high wind speed.

Following Laval et al. (1981), the turbulent eddy diffusivity is computed as

$$
K_{z}=\max \left(l^{2}\left\|\frac{\partial \vec{V}}{\partial z}\right\| \sqrt{1-R i / R i_{c}}, K_{\min }\right)
$$

where the mixing length $l$ is prescribed as $l=$ $l_{0}\left(p / p_{s}\right)^{2}$ with $l_{0}=35 \mathrm{~m}, R i=\frac{g}{\theta} \frac{\partial \theta}{\partial z} /\left\|\frac{\partial \vec{V}}{\partial z}\right\|^{2}$ is the local Richardson number and $R i_{c}(=0.4)$ is a critical Richardson number. Over continents and ice, the value of the minimum diffusivity, $K_{\min }=10^{-7} \mathrm{~m}^{2} \mathrm{~s}^{-1}$, was tuned in order to get the right strength for the polar inversion (Krinner et al., 1997; Braconnot, 1998; Grenier et al., 2000). Over oceans, in order to obtain a satisfactory contrast between trade wind cumuli and strato-cumuli on the eastern borders of basins, a diffusion coefficient $K_{z}$ is first computed with a very small minimum diffusivity $K_{\min }=10^{-10} \mathrm{~m}^{2} \mathrm{~s}^{-1}$, which tends to produce a strong overestimate of boundary layer cloud coverage over the oceans (Grenier, personal communication). A second ad-hoc (and generally stronger) diffusivity, $K_{z}=\xi l^{2}$ with $\xi=0.002 \mathrm{~s}^{-1}$, is used if the temperature inversion at the boundary layer top is weak (in practice if the maximum value of the vertical gradient of potential temperature, $-\partial \theta / \partial p$, is larger than $0.02 \mathrm{~K} / \mathrm{Pa}$ ). The first coefficient is mainly active in the subsidence regions, especially on the East side of oceanic basins. The second one produces smaller (in fact too small) cloud covers in regions of trade wind cumuli.

\subsection{Surface processes}

For coupling purposes, a fractional land-sea mask is introduced in the model. Each grid cell is divided into 4 sub-surfaces corresponding to continental surface, free ocean, sea-ice and ice-sheet. Surface fluxes are computed using parameters (roughness length, albedo, temperature, humidity etc..) adapted to each surface type. For each atmospheric column, vertical diffusion is applied independently for each subsurface, and the resulting tendencies are averaged. An interface model is introduced which separates surface and atmospheric processes. The calculation of surface fluxes is done in an independent model, to which the sensitivities of the fluxes to temperature have to be provided in order to preserve the properties of the implicit scheme as described by Dufresne and Grandpeix (1996) and Marti et al. (2005). With this formulation the flux model can be either a routine in the atmospheric model, an ocean model or a land surface scheme.

For continental surfaces, thermal conduction is computed with a 11-layer model following Hourdin et al. (1993). The bucket model used in previous versions to compute soil moisture and evaporation ${ }^{4}$ is replaced in LMDZ4 by the two-layer hydrological scheme (inspired from Jacquart and Choisnel, 1995) of the ORCHIDEE surface-vegetation-atmosphere transfer and dynamic vegetation model (de Rosnay et al., 2002; Krinner et al., 2005). Computation of the evapotranspiration depends on the plant functional type. Seasonally varying plant leaf area index is prescribed after satellite data (Myneni et al., 2002). Details are given by Krinner et al. (2005). Note that a numerical problem in the surface scheme was identified after the realisation of the IPCC simulations. It produces occasionally very cold temperatures over one time-step in very dry continental regions in the tropics. Although a more robust and improved version of this surface model

\footnotetext{
${ }^{4}$ In the bucket model, the soil water content is described as a single reservoir height $h$ which evolves according to the net water budget $P-E$ (Precipitation minus Evaporation); $E=\beta E_{p}$, where $E_{p}$ is the potential evaporation (that of a free surface of water $)$ and $\beta=\min \left(1, h / h_{p}\right)$ with $h_{p}=75 \mathrm{~mm}$. Water in excess of the maximum content $\left(h_{\max }=150 \mathrm{~mm}\right)$ is lost through runoff.
} 
is now available, the same version as for the IPCC simulations is used here, on purpose.

\section{Basic elements of model clima- tology}

In this section, we present elements of climatology of the LMDZ4 model using simulations which follow the protocol of the Atmospheric Model Intercomparison Project (AMIP, see Gates, 1992) ${ }^{5}$. An ensemble of 5 AMIP simulations covering the 1979-2002 period has been performed. Each simulation differs from the others only by the initial state of the atmosphere, which is issued from 5 different 1st January of a previous AMIP II experiment. The monthly sea surface temperatures and sea-ice boundary conditions constructed at PCMDI (Program for Climate Model Diagnosis and Intercomparison) (Taylor et al., 2000) are first interpolated on the LMDZ grid and then to daily values using cubic-splines.

\subsection{Mean meridional structure}

Fig. 1 presents, in latitude/pressure coordinates, the zonally averaged zonal wind, temperature and relative humidity for mean January and July conditions (grey scales). The thick superimposed contours show the difference with the European Re-Analysis (ERA40) of ECMWF for the same period.

First, and contrary to previous versions of the LMD model, LMDZ4 no longer shows a systematic cold bias in the lower troposphere. A significant cold bias however persists at the tropopause $(100-300 \mathrm{hPa})$ in the extra-tropics. The model tends to be drier than ERA40 in the ITCZ region and wetter in mid-latitudes, with a maximum difference of about $15 \%$ in the roaring forties in July. The intensity of the winter jets is generally somewhat overestimated. The summer jets maximum intensity is better reproduced. A systematic shift toward the equator can also be seen from the dipolar structure in the difference with ERA40 with positive difference equatorward and negative difference poleward of the jet.

To evaluate the cloudiness in terms of cloud types and cloud properties, we compare the model with the International Satellite Cloud Climatology Project (Rossow and Schiffer, 1999) ISCCP-D2 data. To

\footnotetext{
${ }^{5}$ The AMIP II experimental protocol requirements are all fulfilled for the simulations presented here, except that the model was not explicitly spun-up at the beginning of the AMIP period. Instead, each simulation starts from a "quasi-equilibrium" state corresponding to a previous AMIP II simulation for which there was no perceptible trend in deep soil temperature and moisture.
}

be consistent with observations, we use the so-called "ISCCP simulator" (Klein and Jakob, 1999; Webb et al., 2001) that emulates the satellite view of clouds using as inputs the vertical profiles of convective and large scale cloud amounts simulated by the model. The model simulates reasonably well the latitudinal distribution of high clouds, with an overestimate of the high thick clouds at mid latitudes (Fig. 2). The thin and medium mid clouds are strongly underestimated. The low thin clouds are underestimated, the mid low clouds are overestimated at mid and high latitudes, whereas the thick low clouds have a reasonable latitudinal distribution. The LMDZ model displays biases which are common to other GCMs (see e. g., Zhang et al., 2005).

Additional diagnostics more specific of low, mid or high latitudes are detailed below.

\section{$3.2 \quad$ Tropics}

Regarding the tropics, we show in Fig. 3 the structure of the rainfall and net cloud radiative forcing.

In January, the model predicts a maximum of rainfall in the region of the Indonesian oceanic continent, in qualitative agreement with observations. The strong maxima simulated on the major islands in this region are however irrealistic. Over continents, the maximum rainfall is also rather well located with a correct intensity but with a tendency to "confine" the precipitation regions. There is a lack of precipitation over the amazonian delta for January and over Sahel and North-West India for July. The rainfall monsoon is also underestimated on the West coast of India and overestimated over the Indian sub-continent. The maximum over Bay of Bengal has almost the good intensity but it is shifted to the south when compared to Xie and Arkin (1997) climatology.

The distribution of the net cloud radiative forcing is compared to the data of the Earth Radiation Budget Experiment (ERBE, Barkstrom, 1984) on the right panels of Fig. 3. The strong positive bias on the West tropical Pacific Ocean in the winter hemisphere and over Sahara is due to an overestimate of the longwave radiative forcing by high clouds. The negative radiative forcing is also not strong enough over the regions of tropical rainfall on continents, due to an underestimate of the shortwave cloud radiative forcing. However, this bias is partly explained over South America by the underestimate of the convective activity itself (and associated rainfall). One can notice a good representation of the seasonal cycle of cloud forcing (by strato-cumulus clouds) on the east side of oceanic basins (with a maximum in local summer) and a good 

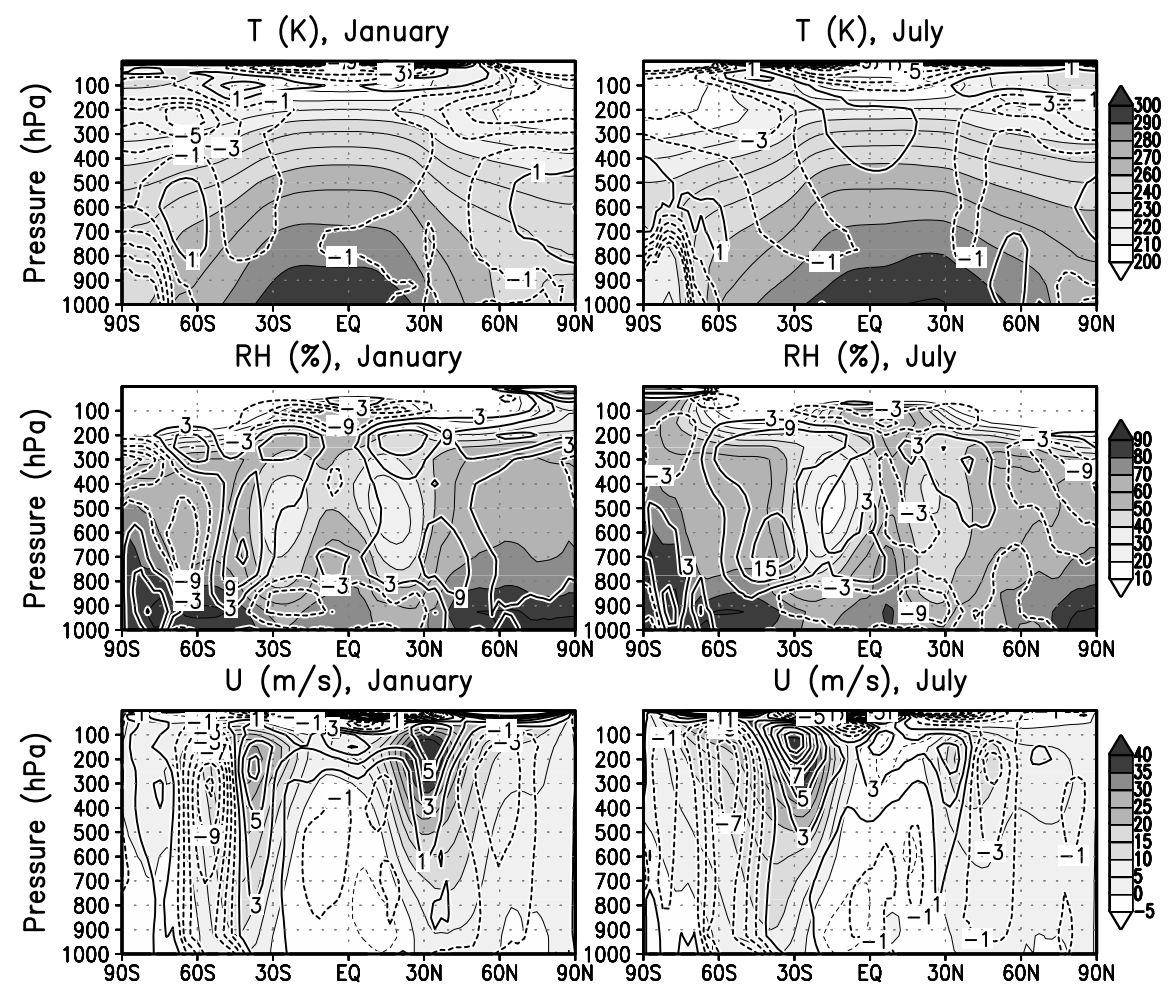

Figure 1: Zonally averaged temperature $(T, \mathrm{~K})$, relative humidity $(R H, \%)$ and zonal wind $\left(U, \mathrm{~m} \mathrm{~s}^{-1}\right)$ simulated for the AMIP period (grey scale) in January (left) and July (right). The model results are averaged over the 5 simulations and for the period 1980-2002. The difference with the ERA40 reanalysis is superimposed with regular (thick) contours (2 K for T, $6 \%$ for $R H$ and $2 \mathrm{~m} \mathrm{~s}^{-1}$ for $U$ ).
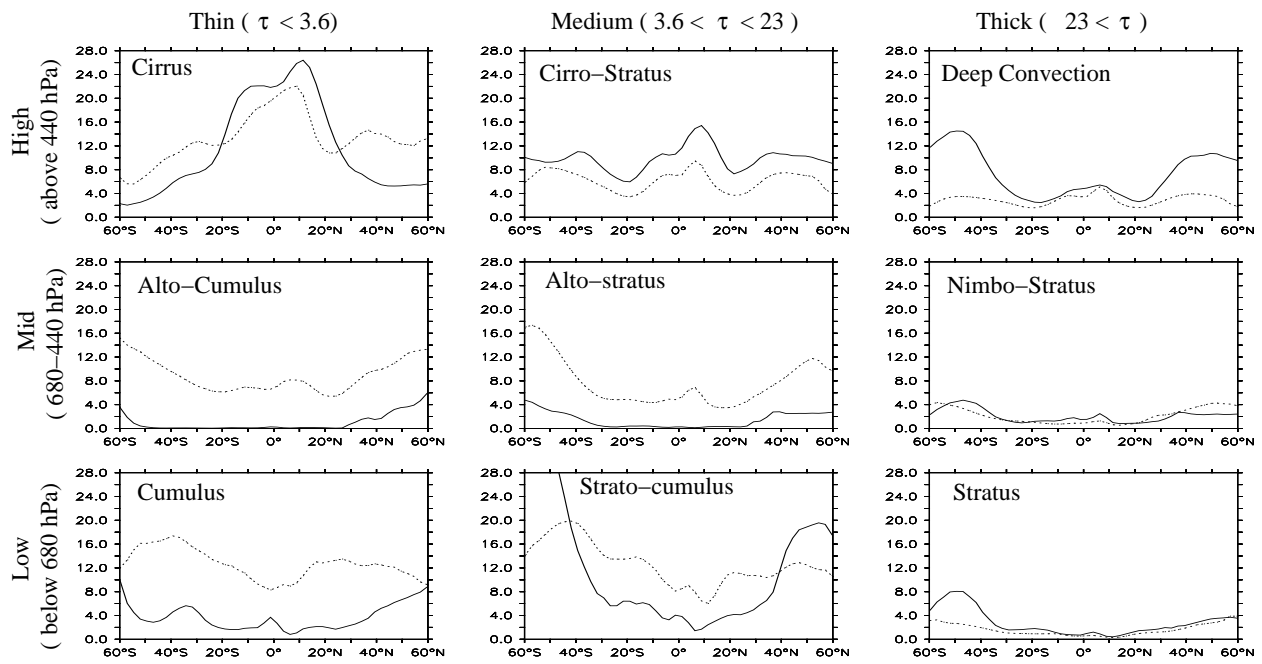

Figure 2: Zonal and annual mean of the nine ISCCP cloud types issued from the ISCCP-D2 satellite data (dashed) and simulated (full curves) by the LMDZ control run. The nine ISCCP cloud types are defined by three bins of cloud-top pressures (displayed on the left) and three bins of optical thickness $\tau$. 
January
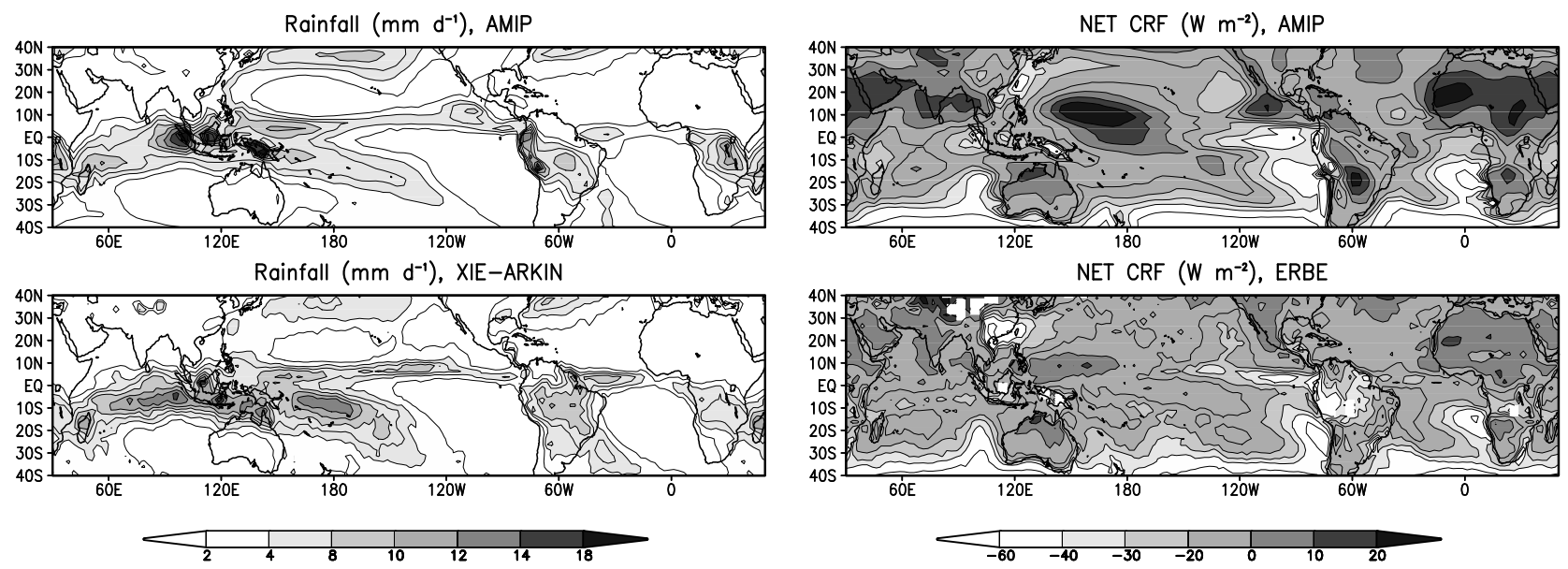

July
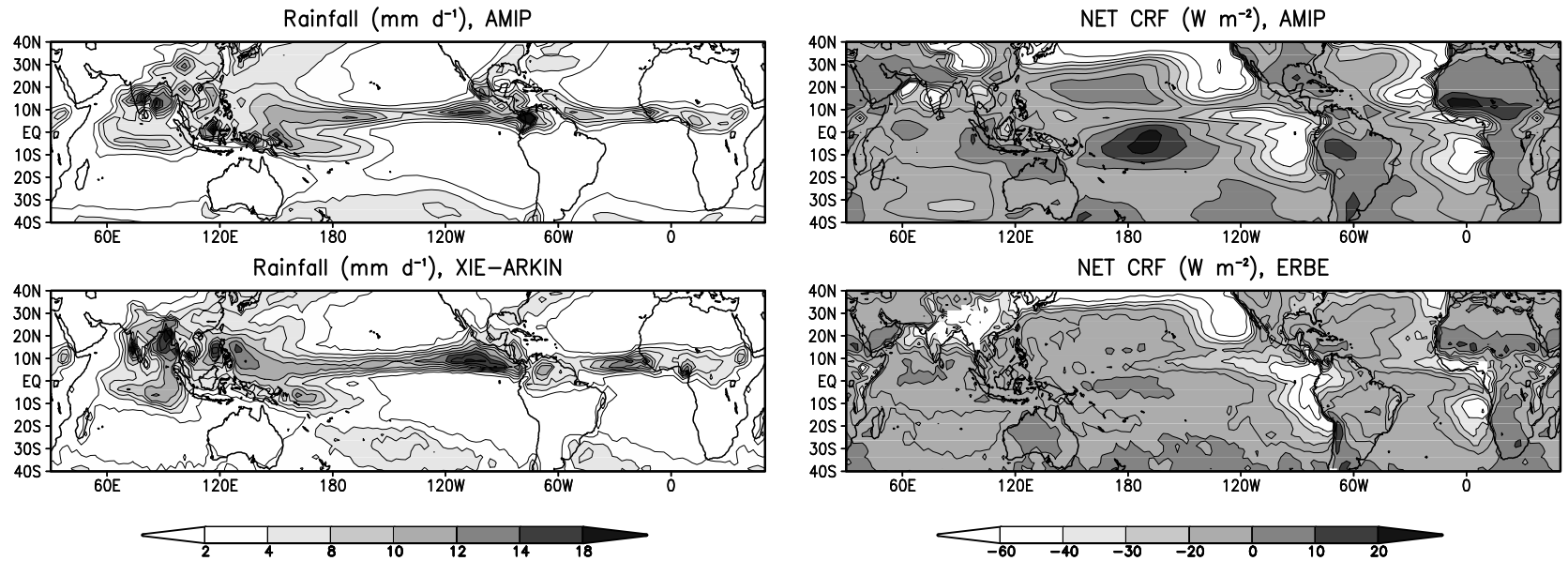

Figure 3: Averaged precipitation $(\mathrm{mm} / \mathrm{d})$ and net cloud radiative forcing $\left(\mathrm{W} \mathrm{m}^{-2}\right)$ for the ensemble mean of the AMIP simulations over the period 1980-2002 and for the Xie and Arkin (1997) and ERBE observations. 
longitudinal contrast over oceans (especially for the summer hemisphere).

\subsection{Mid latitudes}

\section{Steady and transient planetary waves}

For conciseness, and because the variability is largest during winter, we show results for December-JanuaryFebruary in the Northern Hemisphere and June-JulyAugust in the Southern Hemisphere.

For the Northern Hemisphere, the averaged geopotential at $700 \mathrm{hPa}, \mathrm{Z} 700$ (Fig. 4, panels a), presents two major troughs at the east coasts of America and Asia, and two major ridges over Northeastern America and Northeastern Europe. There is a less pronounced trough over Central Europe and a weak ridge to its East (i.e. to the North of the Himalayan plateau). These features are well predicted in the model (left side of Fig. 4) when compared to the reanalysis (right side). This, in part, results from the action at low level of the Subgrid Scale Orographic scheme (Lott, 1999). The model however slightly overestimates the ridge over the Rockies but underestimates the difluence of the jet over western Europe. The systematic shift of the simulated jets toward the equator is also visible on those maps.

The Root Mean Square (RMS) of Z700 (Fig 4) reveals two centres of action, slightly to the west of the two major ridges in Fig. 4a. The location of these two centres of action is realistic when compared to reanalysis. The model nevertheless seems to slightly overestimate the tropospheric variability over the North eastern Pacific. As the total variance in the atmosphere is dominated by the low-frequency variability (Sawyer, 1976; Blackmon, 1976), the RMS fields in (panels b) hide the transient eddies resulting from the baroclinic instabilities generated where the mid-latitude jet is intense (on the lee side of the two major troughs in panels a). To isolate these baroclinic eddies, we next use the procedure of Hoskins et al. (1996) and define the high pass transient fields by the difference between the daily field and the centred box-car 3day mean of that field. The RMS of this high pass field (Fig. 4c) shows baroclinic storm tracks located at the two jet exits, with maximum variance over the western half of the two oceans and extension over the entire oceanic basins. Note nevertheless that the model underestimates substantially the high pass RMS over the entire Pacific.

For the Southern Hemisphere winter, the climatological mean flow (Fig. 4d) is much more zonal. Around $60^{\circ} \mathrm{S}$, it presents enhanced variance over nearly half the globe, with a maximum over southern east Pacific near the Drake passage (Fig. 4e). The pattern of high fre- quency in Fig. 4f presents enhanced variance slightly to the north of the maximum of total variance in Fig. 4e. It covers more than half the globe around $50^{\circ} \mathrm{S}$. Again, these patterns are rather realistic, with the model overestimating the total variance and underestimating the high pass variance.

\section{Interannual variability}

A large number of spatial patterns and indices has emerged in studies of the northern hemisphere wintertime extra-tropical variability. Recently, Quadrelli and Wallace (2004) have shown that they can all be almost fully retrieved by a linear combination of only two basis patterns: the leading two Empirical Orthogonal Functions (EOF) computed by a principal component analysis of the monthly sea level pressure (SLP) field. EOF1 of the ERA40 SLP for the 1980-2001 period (Fig. 5) is a quasi-zonally symmetric dipole between the polar and mid-latitudes also called the Northern Annular Mode or Arctic Oscillation (Thompson and Wallace, 1998). EOF2 is a wavy pattern with a large centre of action over the Pacific and a weaker secondary wave train over Europe. The two EOFs are orthogonal by construction.

Following Quadrelli and Wallace (2004), the first 2 EOF of each simulation are projected on the two basis patterns. In the right panel of Fig. 5, each EOF is represented by a line whose projections on the horizontal and vertical axes give the correlation with the basis EOF 1 and 2, respectively. The lines gather around the two axes with a spread indicative of the variability between different simulations. An ensemble EOF, computed from all experiments together, is also shown. The simulated patterns of variability correlate very well with the observed basis functions, particularly for EOF1 which is the larger scale pattern.

\subsection{High latitudes}

In polar region, the climate is often rather poorly represented in global models (Chen et al., 1995). The data are also scarce and the quality of gridded datasets often remains questionable. Here we compare model output to station measurements over the relatively uniform plateau regions in the centre of the ice sheets. Fig. 6 shows the simulated (but altitude-corrected following Krinner and Genthon (1999)) and observed (Automatic Weather Stations Project, 2004; Automatic Weather Stations Greenland Project, 2004) monthly mean surface air temperatures at Summit (Central Greenland) and Dome C (Central East Antarctica). The model reproduces rather correctly the observations apart from a cool bias at Summit. This cool bias is probably caused by an underestimate of the 

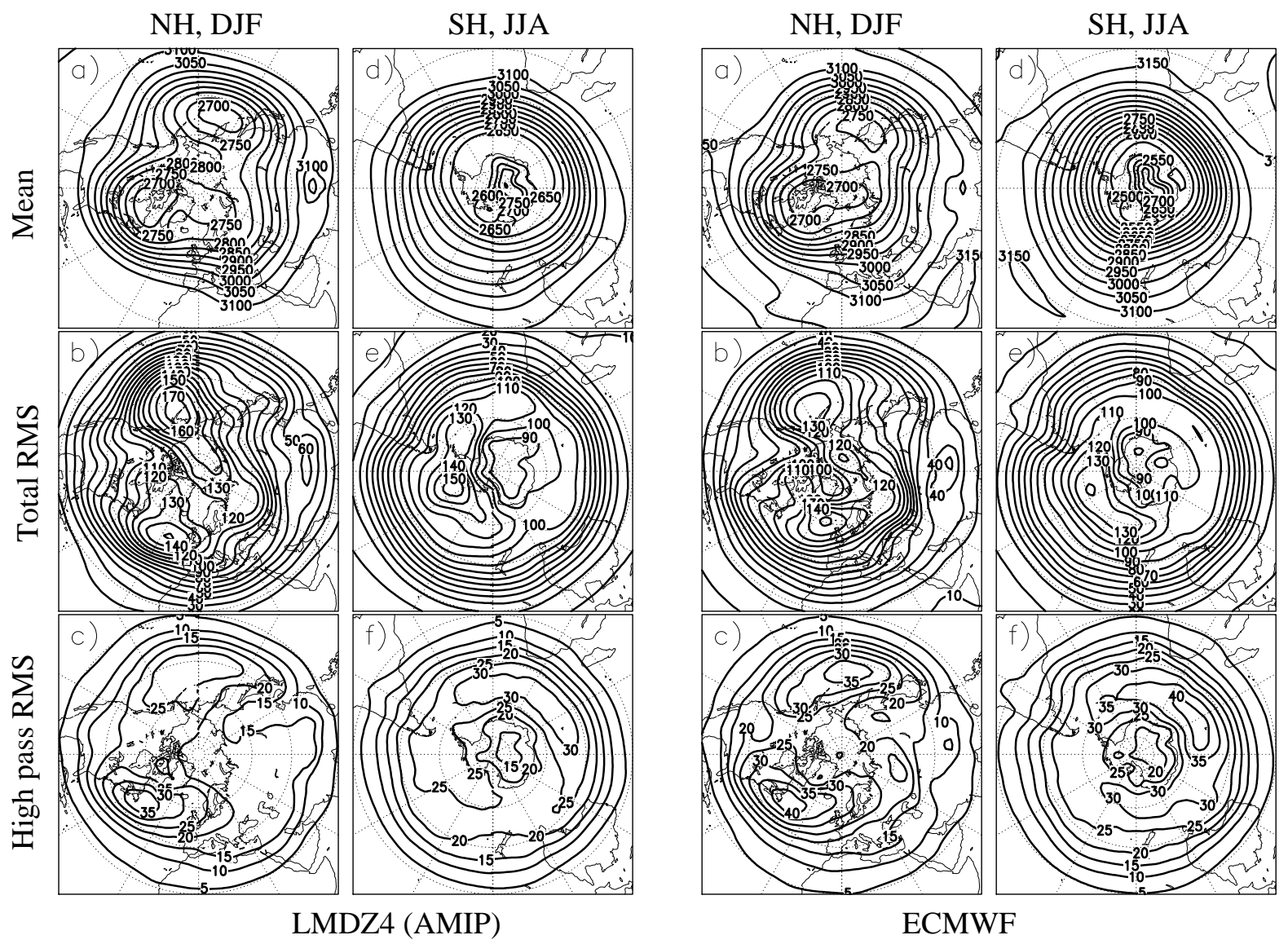

Figure 4: Winter statistics of 700hPa geopotential height for 20 winters and from the LMDZ4 model (left side) and ERA40 ECMWF analysis (right side) for the the Northern Hemisphere in December-January-February (NH, DJF) and for the Southern Hemisphere in June-July-August (SH, JJA). (a)-(d) winter mean, contour interval 50m; (b)-(e) RMS, contour interval 10m; (c)-(f) RMS high pass, contour interval 5m
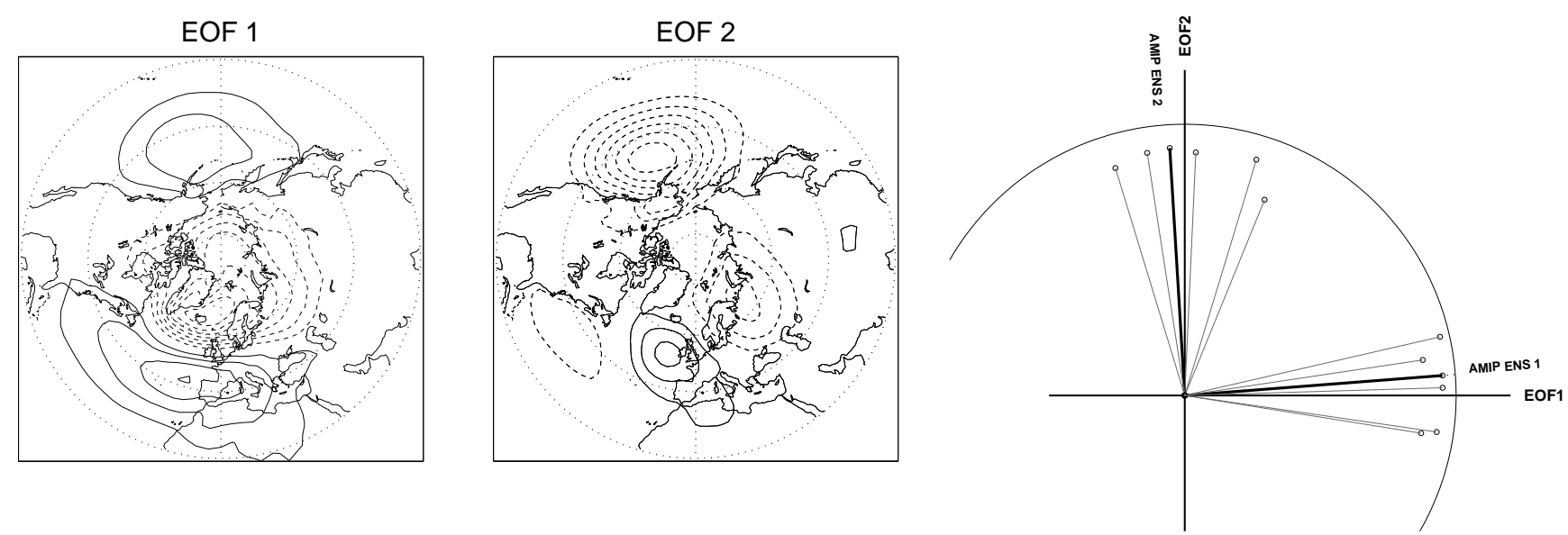

Figure 5: Leading 2 EOF of monthly wintertime northern hemisphere SLP, 1980-2001 (Contours every 1hPa) and projections (area-weighted correlations) of the EOF of the different simulations on the phase space defined by the two EOFs. For reference, a circle of radius unity is plotted. Thin lines are individual simulations, the thick lines are for the ensemble. 


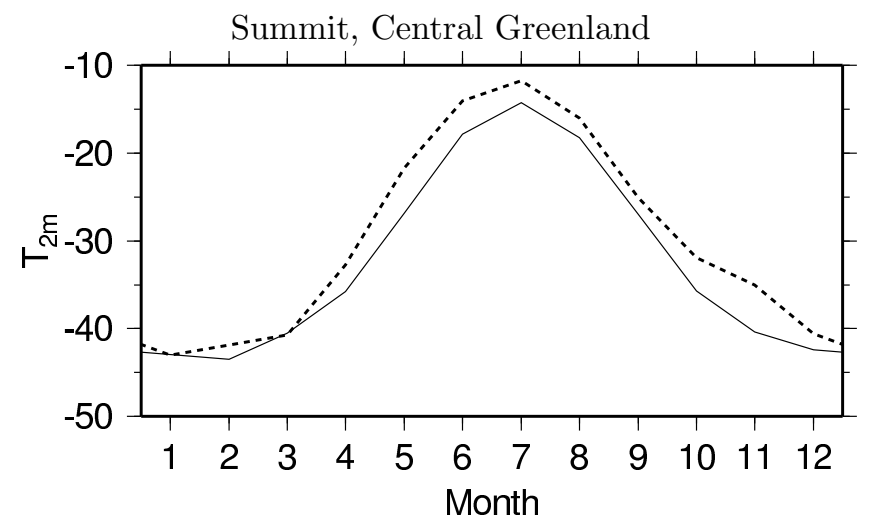

Dome C, Central East Antarctica

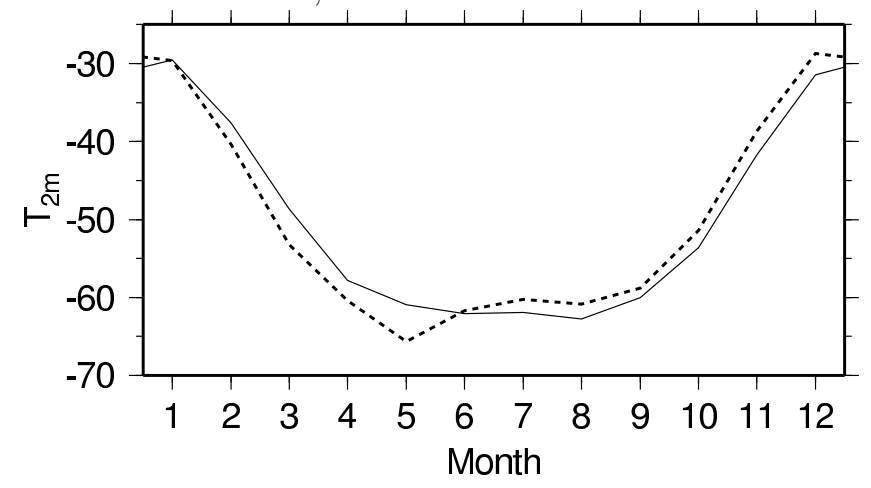

Figure 6: Monthly mean surface air temperatures at Summit $\left(38^{\circ} \mathrm{W}, 72^{\circ} \mathrm{N}, 3250 \mathrm{~m}\right.$ asl $)$ and Dome C $\left(123^{\circ} \mathrm{E}\right.$, $75^{\circ} \mathrm{S}, 3300 \mathrm{~m}$ asl) as simulated with LMDZ4 (full curve, AMIP simulation) and observed (dashed).

downwelling longwave radiation, a relatively frequent model bias over ice sheets (e.g., King and Connolley, 1997). In Antarctica, the smaller bias probably comes from an error compensation. As noted by Krinner et al. (1997), the orographic roughness calculated from the subgrid variability of surface altitude is often too high (as is the case here) over the ice sheet escarpments, which are in reality smooth sloping surfaces. It leads to an underestimate of the surface wind speed over the continent margins and of the intensity of the Antarctic katabatic drainage flow in general (James, 1989). Sensitivity tests with strongly decreased orographic roughness have shown strongly increased, and more realistic, surface wind speeds in Antarctica, but a strong cooling (about $5^{\circ} \mathrm{C}$ ) over the continent.

In the two polar sites considered here, with rare blowing snow and no melt, the surface mass balance is easy to measure through shallow firn cores and is simply the difference between precipitation and sublimation. Surface mass balance at Dome C is $25 \mathrm{~kg} \mathrm{~m}^{-2}$ per year (EPICA community members, 2004); at Summit, it is approximately $220 \mathrm{~kg} \mathrm{~m}^{-2}$ per year (Shuman et al.,
1995). The corresponding values for LMDZ4 are 43 $\mathrm{kg} \mathrm{m}^{-2}$ per year for Dome C and $146 \mathrm{~kg} \mathrm{~m}^{-2}$ per year for Summit. High resolution $(60 \mathrm{~km})$ simulations over Antarctica with a zoomed version of the same model (Krinner et al., submitted) yield a surface mass balance of $31 \mathrm{~kg} \mathrm{~m}^{-2}$ per year at Dome C, which is closer to the observed value.

Over Antarctica as a whole, the average simulated precipitation minus sublimation for Antarctica is 184 $\mathrm{kg} \mathrm{m}{ }^{-2}$ per year, which is not far from the current best estimate of surface mass balance of $166 \mathrm{~kg} \mathrm{~m}^{-2}$ per year (Vaughan et al., 1999). Over the Arctic basin, available gridded precipitation maps (Arctic Climatology Project, 2000) suggest a wet bias (about 25 to $50 \%$ ) of the model.

\section{Sensitivity to parametrized physics}

\subsection{Sensitivity experiments}

A series of sensitivity experiments were conducted by replacing one element or parameter of the reference version. All the sensitivity experiments use climatological SSTs (no interannual variations) corresponding to the mean seasonal cycle of the AMIP boundary conditions. The simulations are performed over 7 years, the last 6 of which are retained for analysis. The following simulations are considered here:

1. CONTROL: Same model version as for AMIP simulations but with climatological SSTs. Used as a control for the sensitivity experiments.

2. TIEDTKE: The convection scheme is switched from Emanuel's to Tiedtke's. The radiative impact of convective clouds is also treated differently as explained above. Both the CONTROL and TIEDTKE simulations are in global radiative balance with a difference of less than $1 \mathrm{~W} \mathrm{~m}^{-2}$.

3. CLOUDSA: The coupling between the convection scheme and cloud schemes (Bony and Emanuel, 2001) is NOT activated.

4. CLOUDSB: Same as CLOUDSA but with a wider PDF for subgrid-scale water $\left(r_{1}\right.$ and $r_{0}$ multiplied by 2 with respect to CLOUDSA). This case is used here to show the impact on the large scale circulation of the radiation tuning and to help analysing the other sensitivity experiments. In terms of the accuracy of the cloud radiative forcing representation, this simulation is not so far 

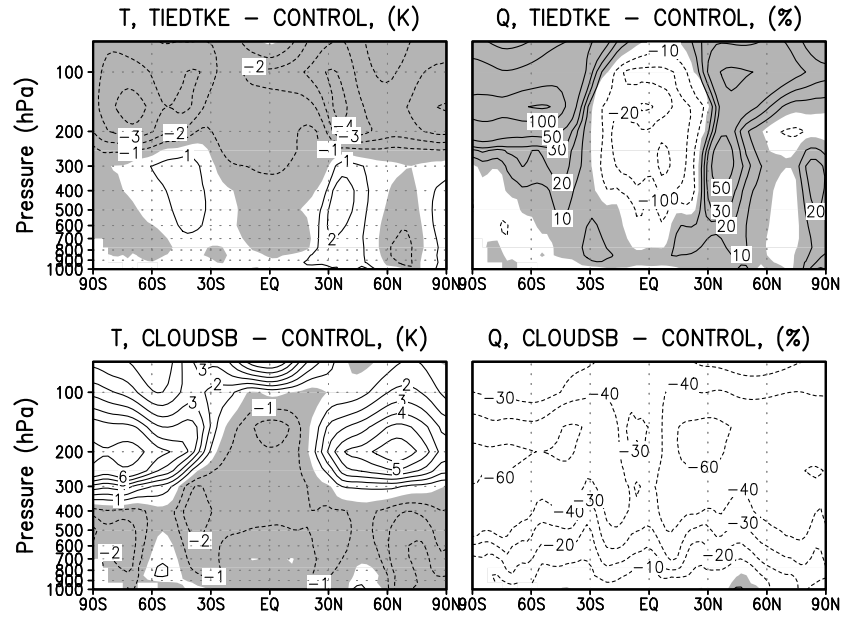

Figure 7: Impact of the convection (TIEDTKE, top) and cloud scheme (CLOUDSB, bottom) on the January mean temperature (left, difference between the sensitivity run and CONTROL) and humidity (right, relative difference between the sensitivity run and CONTROL in \%). We use log pressure on the vertical in order to focus on the tropopause level. The shaded area correspond to a colder (left) and wetter (right) atmosphere in the sensitivity experiment.

from what was typically at work in the previous generation of climate models (e. g. Bony et al., 2004).

5. BUCKET: The bucket scheme is activated in place of ORCHIDEE for the surface hydrology.

An additional simulation (HIGHRES) is performed with the same version of the model as for CONTROL but with a finer horizontal resolution of $1.876^{\circ}$ by $1.25^{\circ}$.

\subsection{Mean meridional structure}

The magnitude of the cold bias of the mid and high latitude tropopause $(100-300 \mathrm{hPa})$ is sensitive to both the convection and cloud schemes. The bias is about twice as strong in the TIEDTKE simulation as in the CONTROL (typically $-8 \mathrm{~K}$ instead of $-4 \mathrm{~K}$ ) in the summer (southern) hemisphere (upper left panel in Fig. 7). On the contrary the CLOUDSB simulation is globally much warmer at the tropopause in the extra-tropics (lower left panel), and even shows a slight warm bias there. In both cases, the difference in temperature is directly related to the humidity change shown in the right panels. At the model tropopause indeed, the radiation alone almost balances the large scale dynamical tendency. The optically thin approximation is also valid so that, in the absence of temperature change, a larger humidity results in a larger cooling to space. For the two cases discussed here, it can be shown that this radiative effect is directly responsible for the modification of the temperature at the tropopause. More precisely, the atmosphere cools (TIEDTKE) or warms (CLOUDSB) until radiation balances the dynamical large scale tendency which is not strongly affected (not shown).

For TIEDTKE, the additional humidity comes directly from a small but systematic import of water by detrainment, due to a so-called "mid-level" convection. This additional convection is active above the main convection which peaks well bellow $300 \mathrm{hPa}$ in mid and high latitudes.

For CLOUDSB, when increasing the width of the $\mathrm{PDF}^{6}$, large scale clouds appear and precipitate well before reaching large scale saturation, which explains the drier atmosphere. Note also that, because of the weaker atmospheric extinction, the longwave radiation escapes more easily from the lower troposphere resulting in a colder atmosphere there.

For all the runs presented here, the zonally averaged rainfall (upper panels of Fig. 8) is overestimated between 40 and $70^{\circ} \mathrm{S}$ for all seasons and underestimated in the southern tropical band in January, when compared to Xie and Arkin (1997) climatology. Note also, for January, an underestimate of the rainfall at $10^{\circ} \mathrm{S}$, corresponding to an underestimate of the South Pacific Convergence Zone. In the TIEDTKE simulation, the rainfall is even slightly stronger at $10^{\circ} \mathrm{N}$ than at $10^{\circ} \mathrm{S}$. The introduction of the Orchidee scheme in place of the old bucket scheme (CONTROL simulation versus BUCKET) for soil moisture results in a decrease of summer rainfall in the mid latitudes over continents, in better agreement with observations as seen in the upper right panel of Fig. $8\left(40-70^{\circ} \mathrm{N}\right)$.

As stated above, particular care was given to the tuning of the cloud radiative forcing, and in particular to its latitudinal variations. The overall agreement with ERBE observations (Barkstrom, 1984) is good, especially in the tropics (intermediate panels in Fig. 8). The CLOUDSA simulation has a weaker (less negative and farther from ERBE observation) shortwave radiative forcing in the tropics. Beyond physical consistency, this is the main reason why the Bony and Emanuel (2001) approach was adopted. The CLOUDSB simulation shows a very good representation of the net cloud radiative forcing in the tropics, but this is due to a compensation between forcings that are too weak in both the longwave and

\footnotetext{
${ }^{6}$ The difference is the same when comparing CLOUDSB with CLOUDSA or CONTROL simulations.
} 
January
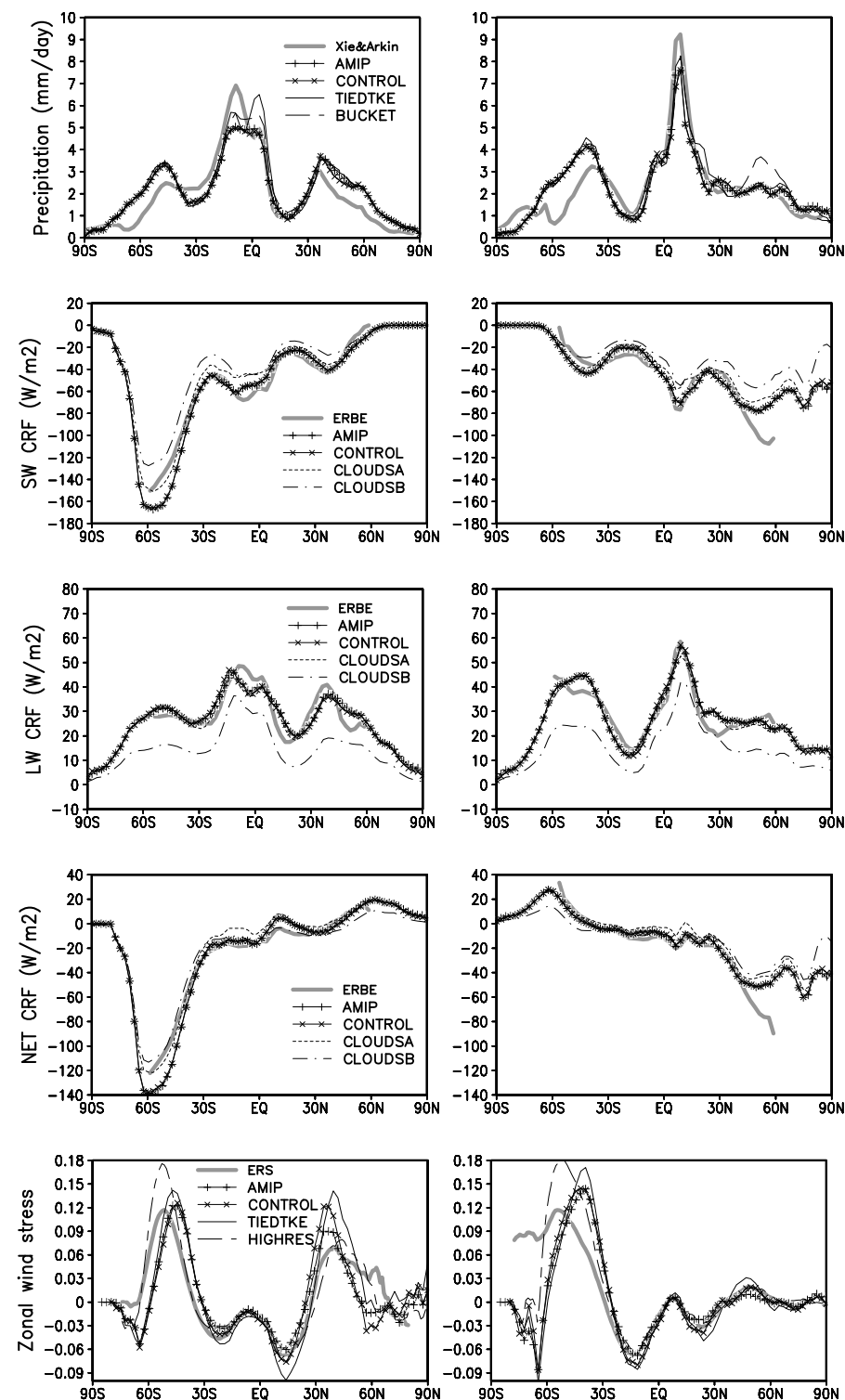

Figure 8: Zonally averaged rainfall $\left(\mathrm{mm} \mathrm{d}^{-1}\right)$; shortwave (SW), longwave (LW) and net (NET) cloud radiative forcing $\left(\mathrm{CRF}, \mathrm{W} \mathrm{m} \mathrm{m}^{-2}\right)$; and wind stress over the ocean $\left(\mathrm{N} \mathrm{m}^{-2}\right)$. Superimposed to observations (grey), we show the AMIP results $(+)$, the CONTROL simulation $(x$, often superimposed) and results of the sensitivity experiments (thin curves). For clarity, each graph only considers a relevant subset of those experiments. Observations are from Xie and Arkin (1997) for rainfall, from ERBE for radiation and from ERS for surface drags. shortwave radiation.

The surface stress (lower panels in Fig. 8) is also a very important quantity for the coupling with oceans. The zonally averaged zonal stress associated with trade winds (local minima around $20^{\circ} \mathrm{N}$ and $20^{\circ} \mathrm{S}$ ) are well simulated for the AMIP and CONTROL simulations when compared to ERS scatterometer data, and slightly too strong for TIEDTKE. The latitudinal shift of the mid-latitude jets is clearly visible on those curves as well as the strong positive impact of an increase of the horizontal resolution (HIGHRES) in that respect.

The finer grid has impact on other aspects of the climatology. The high frequency variability in midlatitudes is for instance much better represented. At the same time, the tendency of the model to confine the tropical precipitations over continents is reinforced. The interpretation of those results is out of the scope of this paper and will not be discussed here.

\subsection{Hadley-Walker circulation}

The large scale distribution of tropical rainfall displays important differences between the sensitivity runs. These changes are usually difficult to interpret because they are often dominated by localised patterns or small shifts in the spatial structure. However, those changes are associated with large scale circulation changes. These changes will be described in this section and will be interpreted in the following one.

\section{Method of analysis}

In order to characterize the tropical large scale circulation in the tropics in the various sensitivity experiments, we first consider the scalar potential $\varphi_{200}$ of the horizontal wind at $200 \mathrm{hPa}$. The scalar potential is defined from the decomposition of the horizontal velocity $\vec{V}$ into its divergent and rotational parts as

$$
\vec{V}=\vec{\nabla} \varphi+\vec{\nabla} \wedge \vec{\psi}
$$

This potential will be called velocity potential $\varphi$. Its Laplacian is also the wind divergence

$$
\vec{\nabla} \cdot \vec{V}=\nabla^{2} \varphi
$$

A local minimum of the velocity potential at $200 \mathrm{hPa}$ corresponds to a horizontal divergence and is generally associated to a large scale ascent in the atmospheric column. This pressure level is generally retained for analysis because the divergence is generally maximum there. This is true on average, but a divergence below $200 \mathrm{hPa}$ can be missed in the velocity potential even for a strong ascent but confined to lower pressures. In order 
$\varphi_{200}$

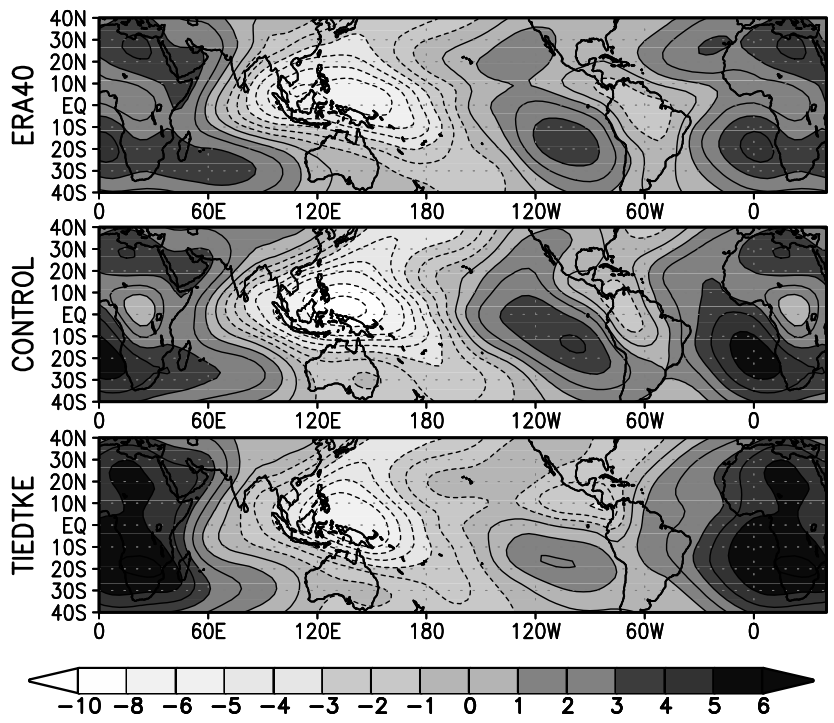

$\tilde{\varphi}$
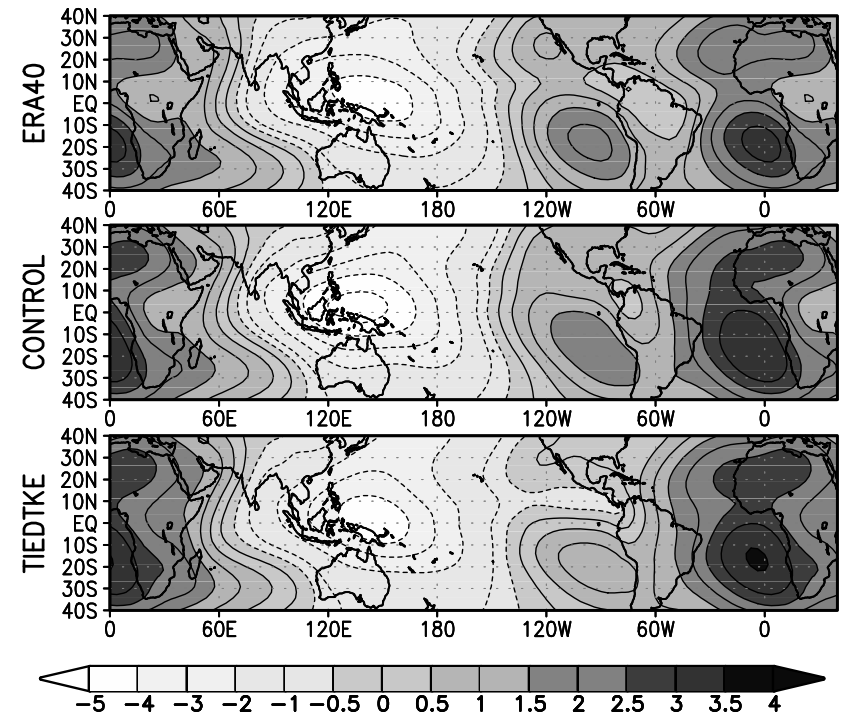

Figure 9: Velocity potential of the wind at $200 \mathrm{hPa}\left(\varphi_{200}\right.$, left, unit $\left.10^{6} \mathrm{~m}^{2} \mathrm{~s}^{-1}\right)$ and of the z-weighted potential $(\tilde{\varphi}$, right, unit $10^{15} \mathrm{~W}$ ); annual mean for the 1980-2002 period for ERA40 and for a 6 -year average for CONTROL and TIEDTKE simulations.

to overcome this problem, we consider also the scalar potential $\tilde{\varphi}$ associated with the vertically integrated horizontal transport of geopotential $\int_{0}^{p_{s}} d p \vec{V} g z$. This potential is close to a $z$-weighted integral of the velocity potential (see Appendix A)

$$
\tilde{\varphi} \simeq \int_{0}^{p_{s}} d p z \varphi
$$

It will be called z-weighted potential hereafter. It is also shown in Appendix A that

$$
\tilde{w} \simeq \frac{1}{g} \nabla^{2} \tilde{\varphi}
$$

where $\tilde{w}$ is the total vertical momentum of the atmospheric column

$$
\tilde{w}=\int_{0}^{\infty} d z \rho w \simeq-\int_{0}^{\infty} d z \frac{\omega}{g}
$$

where $w$ and $\omega$ are the vertical velocity expressed in $z$ and pressure coordinate respectively.

\section{Annual mean potentials}

In the reanalysis, the overall structure of the velocity potential at $200 \mathrm{hPa}, \varphi_{200}$, is characterized by a strong minimum (maximum ascending motion) over the western equatorial Pacific (upper left panel in Fig. 9). Secondary minima, associated with the tropical forests

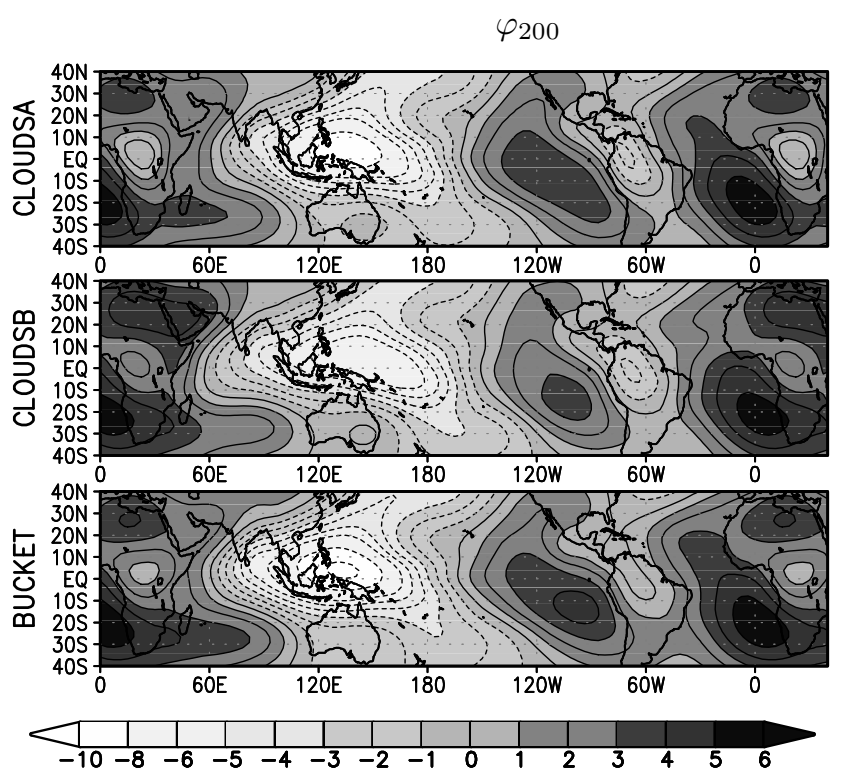

Figure 10: Velocity potential at $200 \mathrm{hPa}\left(\varphi_{200}\right.$, unit $10^{6} \mathrm{~m}^{2} \mathrm{~s}^{-1}$ ); annual mean for a 6 -year average for CLOUDSA, CLOUDSB and BUCKET sensitivity experiments. 
over Africa and Amazonia are also visible as well as the maxima associated with dry subsiding regions on the eastern side of the tropical Atlantic and Pacific oceans.

This structure is reproduced reasonably well in the CONTROL simulation. Among the main differences, one can note that the trough of the equatorial East Pacific is not as marked as in the reanalysis. The minimum over Amazonia is also somewhat more confined and shifted toward central America than in the reanalysis. More quantitatively, one may notice that the velocity potential variation between its minimum on the West and local maximum on the East equatorial Pacific is about $30 \%$ larger in the CONTROL simulation. In comparison, the structure of $\varphi_{200}$ in the TIEDTKE simulation shows significant differences, the most noticeable being the quasi disappearance of the velocity potential minimum over Africa and the shift of the Amazonia minimum towards the equatorial East Pacific.

As expected, the z-weighted potential $\tilde{\varphi}$ maps (right panels of Fig. 9) are quite similar to the velocity potential $\varphi_{200}$ ones. In the CONTROL simulation, most of the comments made from the velocity potential $\varphi_{200}$ remain true, except for the total variation of $\tilde{\varphi}$ over the equatorial Pacific which is quite close in CONTROL and ERA40. This remarks also holds for the contrast between the local minimum over East Africa and local maximum over South Atlantic. For the TIEDTKE simulation, the $\tilde{\varphi}$ field is closer to ERA40 over continents (some z-weighted potential trough is present over East Africa while absent in $\varphi_{200}$ field) but farther over ocean (a strong trough is associated to the ITCZ over the eastern equatorial Pacific).

The two potentials $\tilde{\varphi}$ and $\varphi_{200}$ considered together yield indications about the vertical distribution of vertical velocity. In particular, the fact that the local minima over continents are overmarked in $\varphi_{200}$ but not in $\tilde{\varphi}$ for the CONTROL simulation is indicative of large scale vertical (upward) velocities peaking higher, with a larger wind divergence at $200 \mathrm{hPa}$ than in the reanalysis. The same comparison of $\tilde{\varphi}$ and $\varphi_{200}$ for the TIEDTKE simulation suggests a relatively lower height for the large scale ascent over Amazonia and Africa than in the re-analysis.

For the CLOUDSA experiment (Fig. 10), the $\varphi_{200}$ minima over Africa and Amazonia are deeper than in the CONTROL. It is the opposite for CLOUDSB which tends to mimic the relative weakness of continental ascent in TIEDTKE. The $\tilde{\varphi}$ fields are in fact very close to each other over Africa and Amazonia for the CLOUDSB (not shown) and TIEDTKE simulations. However, the associated minima in $\varphi_{200}$ still appear for CLOUDSB while they are absent for TIEDTKE.
This suggests that the cloud scheme change affects the strength of the large scale ascent, but not its height, whereas the use of the Tiedtke's scheme in place of the Emanuel's both affect the strength of the ascending motions over continents and the vertical profile of the vertical velocity.

Finally, the BUCKET simulation is not very different from CONTROL with possibly a better representation of the large scale ascent over Amazonia but a worse representation of the African trough which is shifted to the East.

\section{Potential and rainfall}

The changes analysed above have significant signature in terms of seasonal rainfall. In January, three of the sensitivity runs (TIEDTKE, CLOUDSB and BUCKET) show a similar and unrealistic maximum of precipitation North-East of Madagascar (Fig. 11, left). This feature is related to a weakening of the large scale ascent over Indonesia (positive difference Fig. 11. right) associated with a weakening of the Walker circulation across the Indian Ocean. In July, a similar weakening of continental ascent in TIEDTKE simulation is associated with a longitudinal structure of wave number 1 (Fig. 12) in the difference of the $\mathrm{z}$ weighted potentials. The large scale ascent is globally weakened in the $0-160 \mathrm{E}$ longitude band, and monsoon rainfall are less abundant over the Indian and African continents. For India itself, this can be considered as an improvement with respect to CONTROL simulation which produces too much rain over the continent and not enough on the West coast.

The Tiedtke's scheme also tends to produce narrow and strong rainfall patterns over oceans. This is especially the case over East Pacific (Fig. 11 and 12) where it is associated with a strong trough in the annual mean velocity potentials $\varphi_{200}$ and $\tilde{\varphi}$ (Fig. 9).

\subsection{Regime sorted analyses}

So far, we have analysed how the different parametrizations affect the large scale Hadley-Walker circulation and the distribution of rainfall. In this section, we try to relate these modifications to the intrinsic behaviour of the parametrizations.

The heating and moistening effect of each parametrization on the atmospheric environment (which corresponds in GCMs to diabatic tendencies of temperature and moisture) depends to a large extent on the large-scale atmospheric circulation in which it is embedded. As the geographical distribution and the intensity of large-scale dynamical patterns generally differ between simulations (as well as between models and 

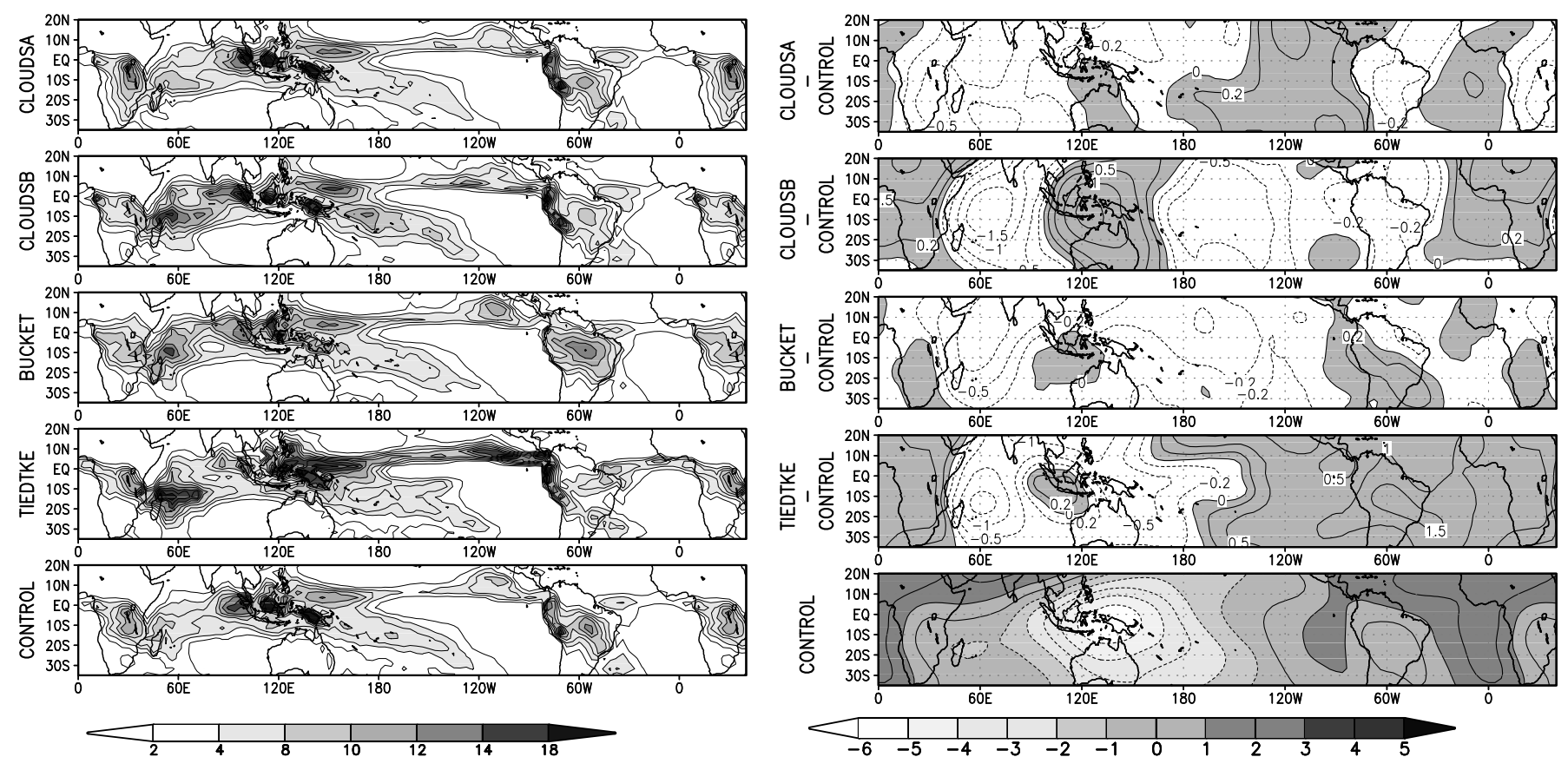

Figure 11: January rainfall (left, $\mathrm{mm} \mathrm{d}^{-1}$ ) and z-weighted potential $\tilde{\varphi}$ (right, unit $10^{15} \mathrm{~W}$ ) for the CONTROL and sensitivity experiments. For the sensitivity experiments, the right panel is the difference of $\tilde{\varphi}$ with that of the CONTROL simulation with same units.
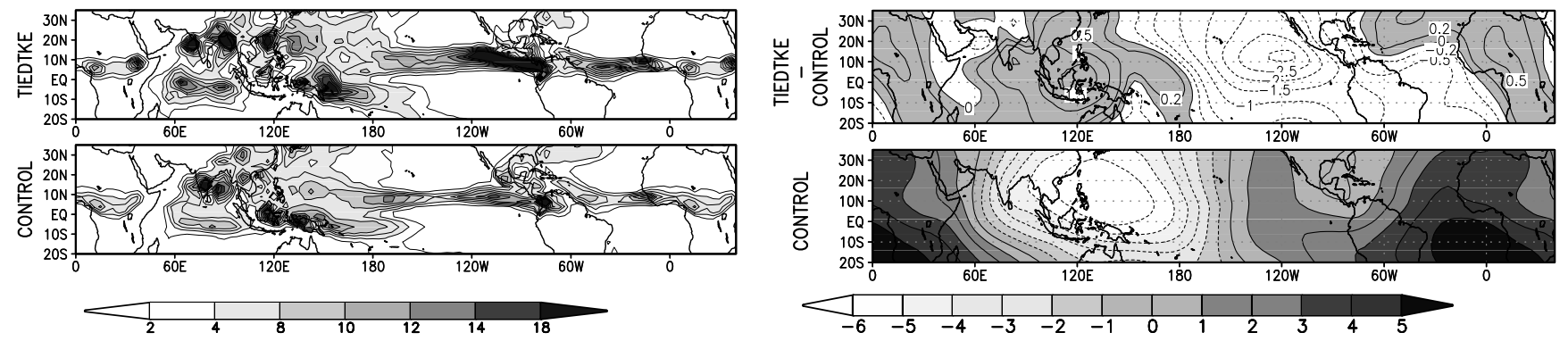

Figure 12: Same as Fig. 11 but for July and CONTROL and TIEDTKE. 


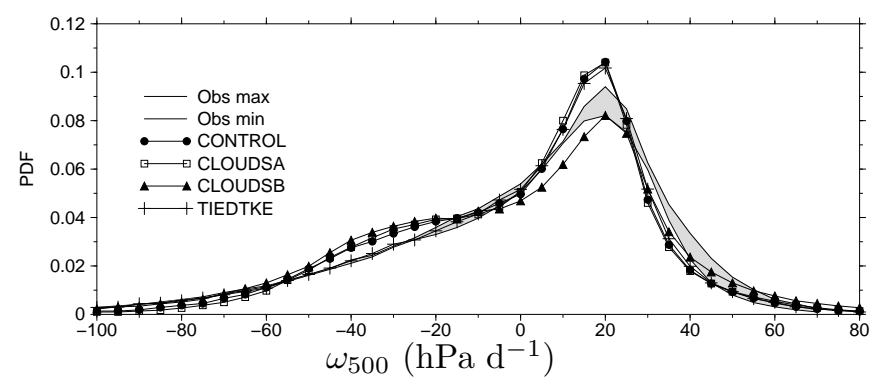

Figure 13: Probability distribution function of $\omega_{500}$ in the 30S-30N latitude band over oceans for two sets of reanalysis (ERA40 and NCEP2 giving rise to the grey area) and for the CONTROL, CLOUDSA/B and TIEDTKE experiments.

observations), it is difficult to analyse and to compare the behaviour of parametrizations by considering only horizontal maps or zonal averages.

To make this comparison easier and to get some deeper insight in how the different schemes work, we adopt the compositing methodology proposed by Bony et al. (1997) which uses the large-scale monthlymean mid-tropospheric $(500 \mathrm{hPa})$ vertical pressure velocity $\omega$ as a proxy for large-scale rising $(\omega<0)$ or sinking $(\omega>0)$ motions. As shown by Bony et al. (1997), and illustrated further below, this method allows to classify the tropical regions according to their convective activity, and to segregate in particular regimes of deep convection from regimes of shallow convection. $^{7}$

This methodology, previously applied to cloud feedback studies (Bony et al., 2004; Bony and Dufresne, 2005; Wyant et al., 2005), is used here to study the behaviour of different parametrizations in the Tropics. Following those previous studies, we keep $\omega_{500}$ as a proxy although $\nabla^{2} \tilde{\varphi}$ is a promising alternative (see Appendix A). The regime sorting is applied to monthly outputs of a 6 years long simulation (i. e. 72 monthly means) for the $30^{\circ} \mathrm{S}-30^{\circ} \mathrm{N}$ region. Given a bin $K$ in vertical velocity, of central value $\omega_{K}$ and width $\delta \omega$ (here $5 \mathrm{hPa} / \mathrm{d}$ ), and for each model variable $X$, the regime sorted value reads $X_{K}=$ $\sum_{(i, m) \in W_{k}} a_{i} X_{(i, m)} / \sum_{(i, m) \in W_{K}} a_{i}$ where $W_{K}$ is the ensemble of pairs of grid indices $i$ and months $m$, for which $\omega_{K}-\delta \omega / 2<\omega_{500(i, m)} \leq \omega_{K}+\delta \omega / 2$ and $a_{i}$ is the area of mesh $i$.

\footnotetext{
${ }^{7}$ In the tropics, nearly all of the upward motion associated with ensemble-average ascent occurs within cumulus clouds, and gentle subsidence occurs in-between clouds. The rate of subsidence in-between clouds being strongly constrained by the clear-sky radiative cooling (which is nearly invariant), an increase of the large-scale mean ascent corresponds, to first order, to an increase of the mass flux in cumulus clouds (Emanuel et al. 1994).
}

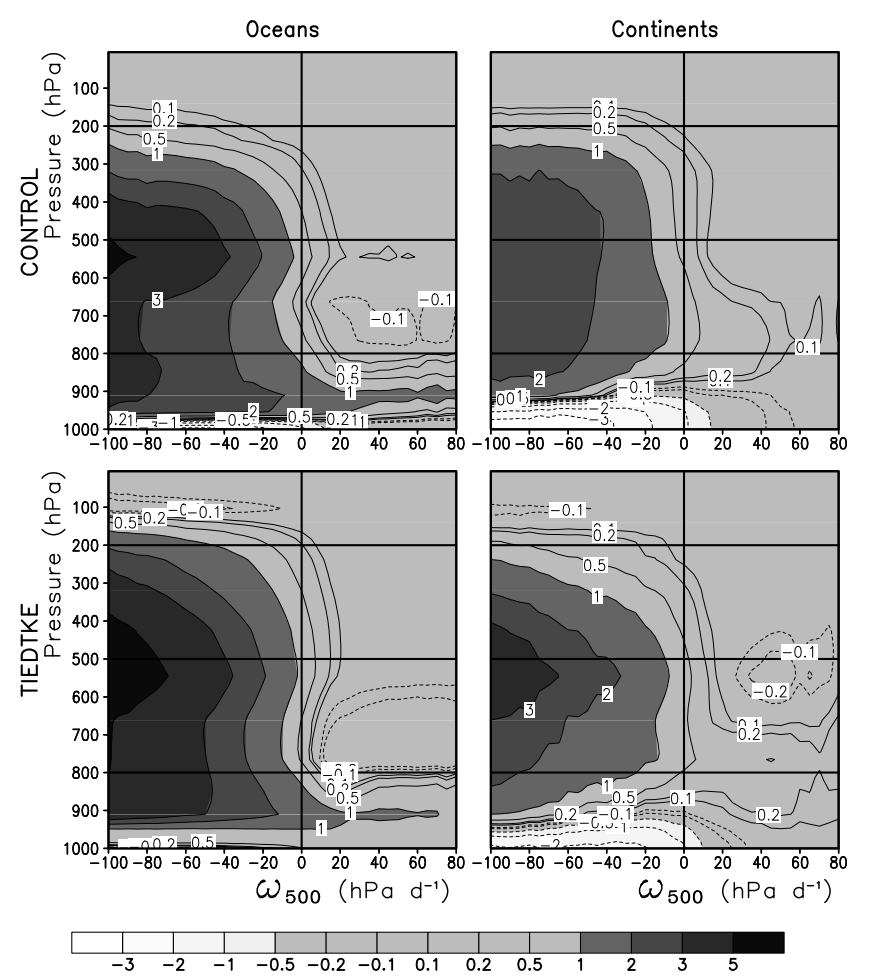

Figure 14: Convective heating rate $\left(\mathrm{K} \mathrm{d}^{-1}\right)$ in a regime sorted diagram (pressure in $\mathrm{hPa}$ versus $\omega_{500}$ in $\mathrm{hPa} \mathrm{d}^{-1}$ ) for the CONTROL (with Emanuel's scheme) and TIEDTKE experiments over oceans (left) and continents (right). Note that the contouring is refined around 0 .

When comparing different parametrizations in this framework, one must keep in mind the underlying probability distribution function which gives the relative weight of the various regimes. The PDF itself is indeed sensitive to parametrization changes (Fig. 13). When compared to the ERA40 and NCEP re-analysis or to the TIEDTKE simulation, the CONTROL simulation with Emanuel's convection scheme seems to overestimate the frequency of the moderate convective regimes $\left(-60<\omega_{500}<-20 \mathrm{hPa} / \mathrm{d}\right)$ and underestimate the very strong convective regimes. Changes in the representation of large scale clouds (CLOUDSB versus CLOUDSA or CONTROL) affects more the PDF in subsidence regimes.

\section{Convection}

In order to compare the convective parametrizations (CONTROL versus TIEDTKE), we shall use a series of regime-sorted versus pressure graphs of the convective heating rate, convective moistening, relative humidity 

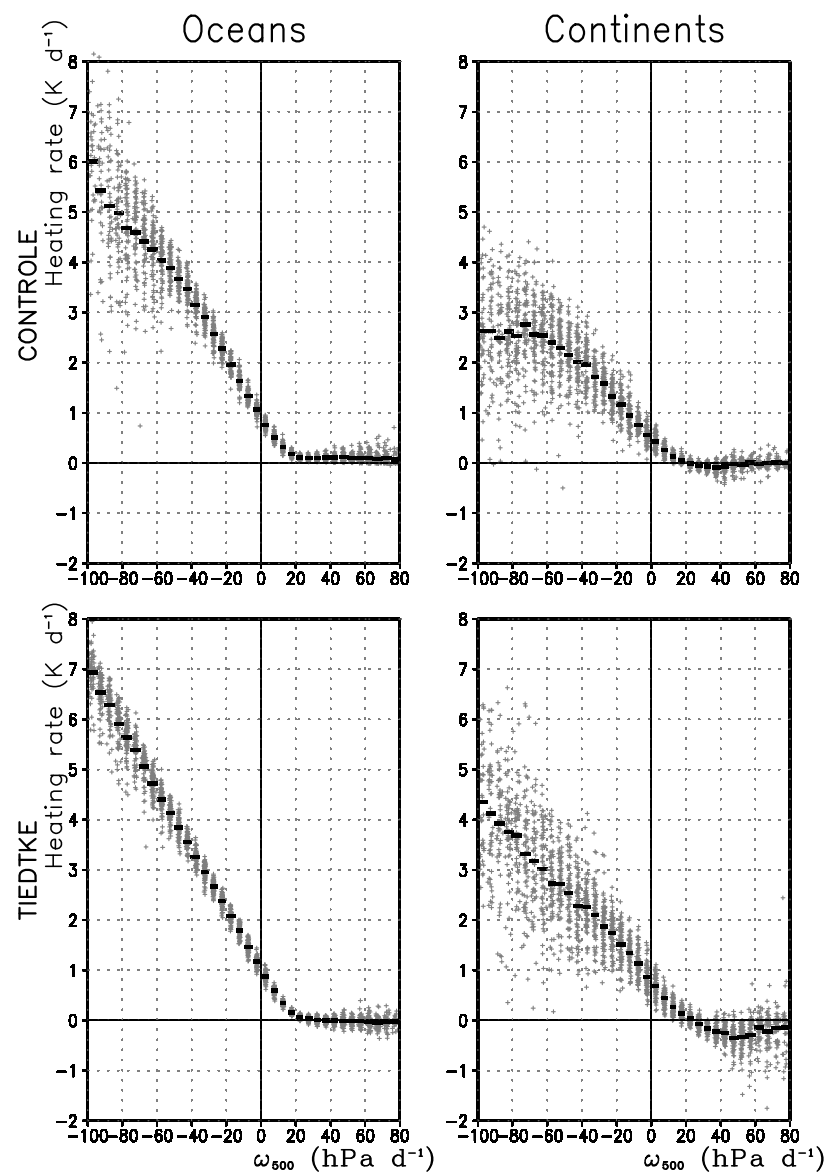

Figure 15: Scatter plot of the convective heating rate $\left(\mathrm{K} \mathrm{d}^{-1}\right)$ at the $550 \mathrm{hPa}$ pressure level, as a function of $\omega_{500}\left(\mathrm{hPa} \mathrm{d}^{-1}\right)$.

and cloud cover.

First we consider the general features of these graphs. Fig. 14 displays the convective heating rate $\omega_{500}$-pressure graphs. In consistency with the above discussion of the link between large-scale vertical velocity $\omega$ and convective activity, we see that the behaviour of convective tendencies and of the atmospheric state is very contrasted between deep convective regimes $\left(\omega_{500}<0\right)$ and shallow convective regimes $\left(\omega_{500}>0\right)$. The difference between continents and oceans is also well marked with, for instance, a cooling by downdraughts in a very shallow layer close to the surface over the ocean and in a much thicker layer over land. The heating rate by convection increases less rapidly as a function of $-\omega_{500}$ over continents because there is less water available there. This contrasted behaviour is further illustrated by a scatter plot (Fig. 15) showing the same heating rates as in Fig. 14 but for the $550 \mathrm{hPa}$ pressure level. Each

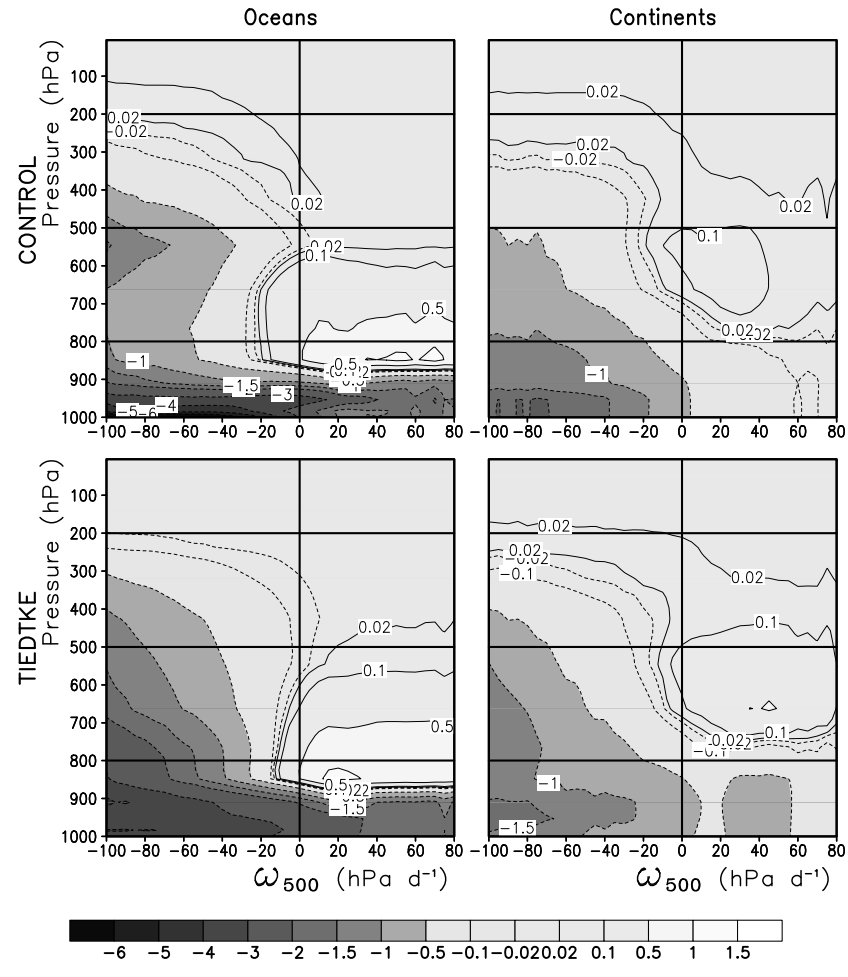

Figure 16: Convective moistening $\left(\mathrm{g} \mathrm{kg}^{-1} \mathrm{~d}^{-1}\right)$ with same conventions as in Fig. 14. Note that the contouring is refined around 0 .

point on these graphs corresponds to one point of the horizontal grid and one of the $6 \times 12$ months of the simulation used to produce the regime sorted analyses. Note the relatively weak dispersion around the mean, especially for intermediate regimes $\left(-50 \mathrm{hPa} \mathrm{d} \mathrm{d}^{-1}<\right.$ $\left.\omega_{500}<0\right)$ over oceans. This is consistent with the picture of a quasi-equilibrium between convection and large scale dynamics in the tropics.

The convective moistening (Fig. 16) is also very contrasted between deep convective regimes $\left(\omega_{500}<0\right)$, where the parametrization essentially dries the whole atmosphere by precipitating water onto the ground, and shallow convective regimes $\left(\omega_{500}>0\right)$, where the water is transported from the surface up to the $850-500 \mathrm{hPa}$ pressure range over oceans (with a similar but weaker effect on continents). Near the surface and for all regimes, the (dominant) effect of downdraughts results from the combination of moistening (and cooling) by evaporation of the falling precipitation and drying (and heating) by downward advection. On continents, because of the relatively weak relative humidity (see Fig. 17), a large part of the precipitation evaporates in the boundary layer, explaining the weak drying and strong cooling there. Over ocean, the near saturated 


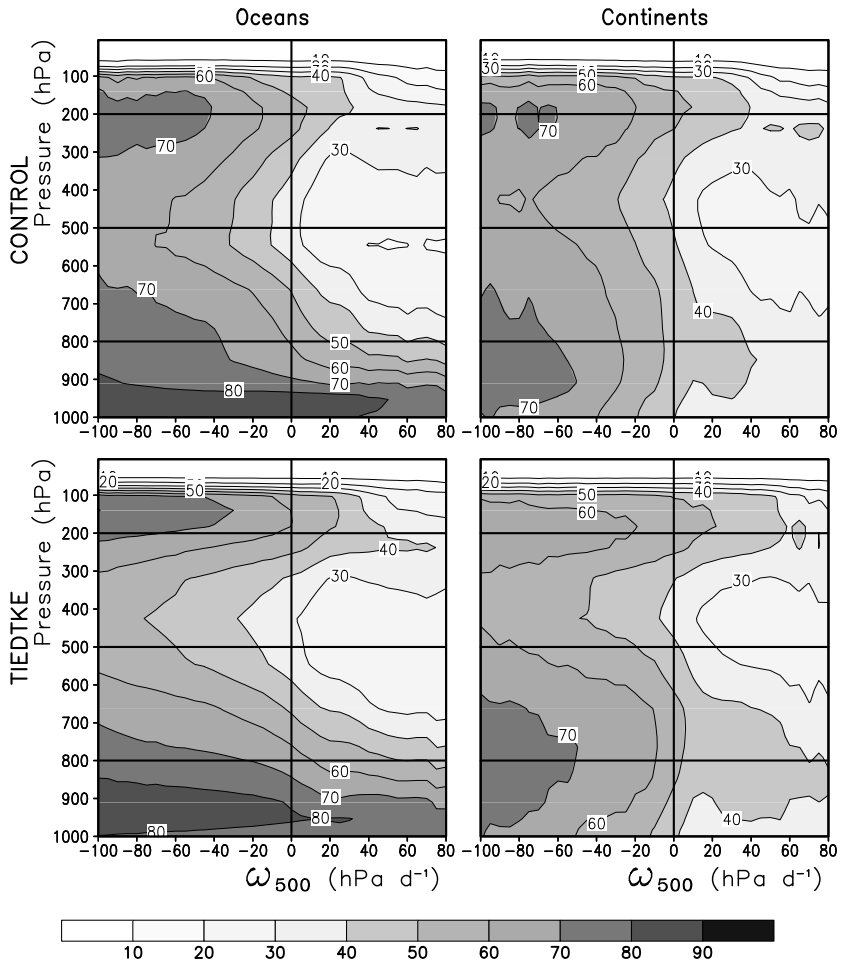

Figure 17: Relative humidity (\%) with same conventions as in Fig. 14.

boundary layer inhibits evaporation and the strong stratification in humidity leads to stronger positive drying and heating by downward advection.

Turning to the comparison of the two convective schemes, the vertical distribution of convective heating (Fig. 14) appears quite different. The Tiedtke's scheme produces a deeper convective heating over oceans than Emanuel's, with a peak at $550 \mathrm{hPa}$. Over continent, the convective heating is more homogeneous on the vertical with Emanuel's, corresponding to a stronger heating above $500 \mathrm{hPa}$. This is consistent with the fact that the marked local minima of $\varphi_{200}$ in the CONTROL simulation over Africa and Amazonia (Fig. 9) have almost no counterpart in TIEDTKE, while both simulations show similar troughs in the same regions for the $\mathrm{z}$-weighted potential $\tilde{\varphi}$. The convective heating is altogether significantly stronger and deeper over ocean than over continent with Tiedtke's while it is somewhat weaker and shallower over ocean than over continent when using Emanuel's scheme.

Another major difference is the much stronger near surface cooling with the Emanuel's scheme. This strong cooling arises from reevaporation of convective rainfall in the unsaturated atmosphere, below the cloud base. This point is further illustrated by a scatter plot of

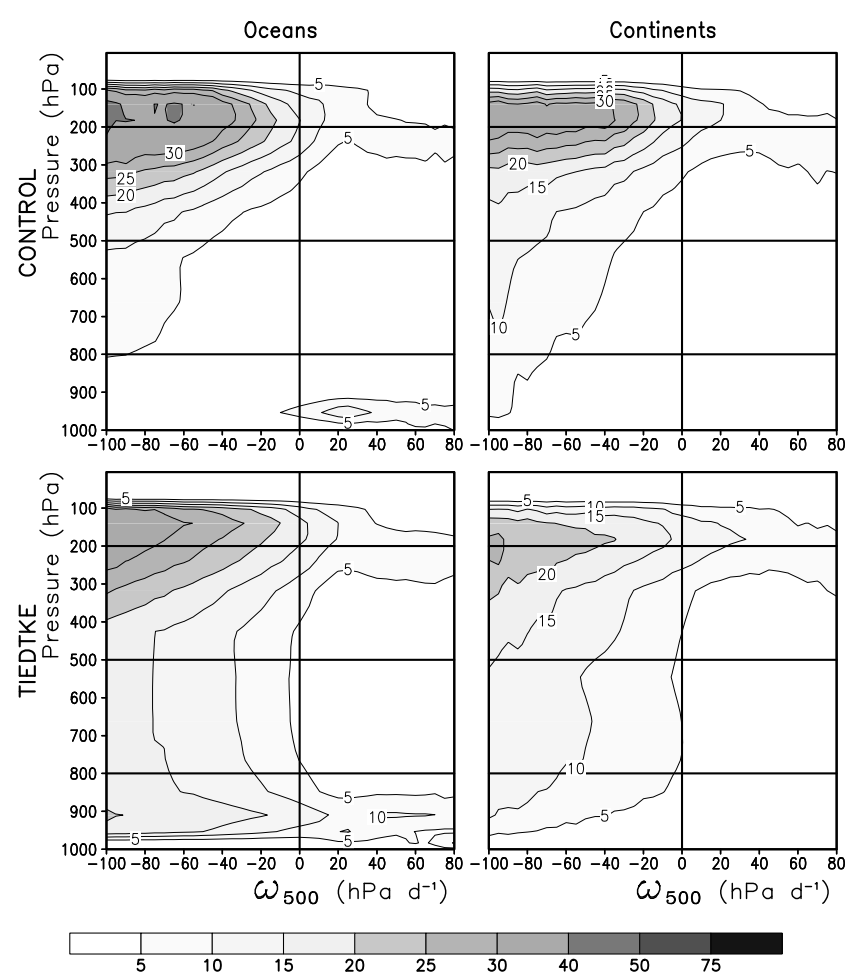

Figure 18: Cloud cover (\%) with same conventions as in Fig. 14.
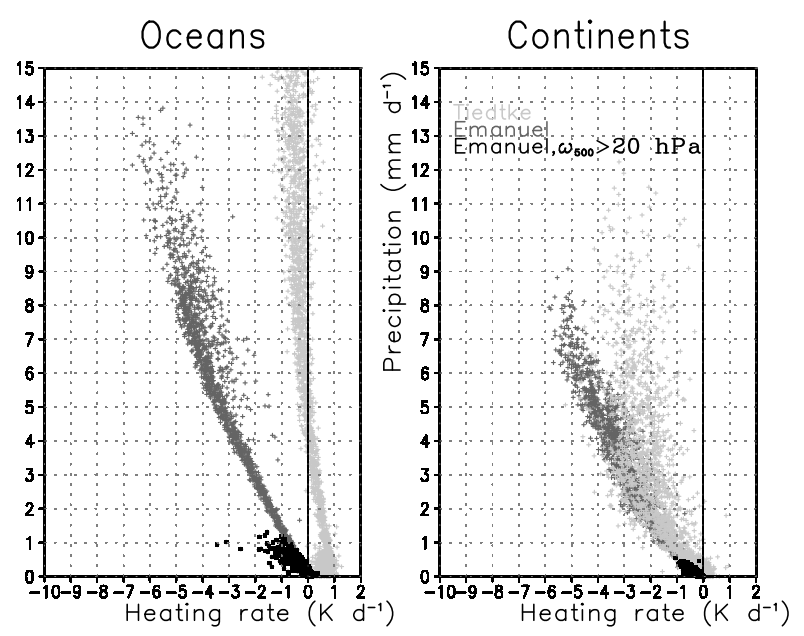

Figure 19: Scatter plot of the convective heating rate at the lowest model level and of the surface precipitation over ocean (left) and continent (right) for the Tiedtke's scheme (light grey crosses), and for the Emanuel's scheme (dark grey: no selection, black: $\left.\omega_{500}>20 h P a\right)$. 
the near surface convective heating rate versus surface rainfall in Fig. 19. Over oceans, the near surface cooling increases rapidly as a function of precipitation for the Emanuel's scheme, with a weak dispersion. The cooling also increases with precipitation for Tiedtke but with much smaller values (typically 0.5 instead of $5 \mathrm{~K} /$ day for Emanuel for a monthly mean precipitation of 10 $\mathrm{mm} / \mathrm{d}$ ).

This cooling associated with convective precipitations is the main mechanism by which convection stabilizes the troposphere (Emanuel et al., 1994). In Emanuel's scheme the closure is a function of the tropospheric stability, which, combined with the near surface cooling, results in a strong self-inhibition of convection. This self inhibition is responsible for the larger occurrence of moderate convective regimes $\left(-60<\omega_{500}<-20\right.$ $\mathrm{hPa} / \mathrm{d}$, Fig. 13), and for the limitation of the convective rainfall and heating rate at $500 \mathrm{hPa}$ visible on the scatter plots (Fig. 19 and Fig. 15 respectively).

With Tiedtke's scheme, the moisture convergence closure does not provide any sensitivity to the atmospheric stability. Some self-inhibition could however be at work since triggering depends on the atmospheric stability, but the stabilization by reevaporation is too weak. The signature of the absence of self-inhibition is visible in the tail of the PDF in strong convective regimes (Fig. 13), and in the very large values reached by convective rainfall (Fig. 19). Note also that the dispersion of heating rates around the mean (Fig. 15) is particularly weak over oceans for the Tiedtke's scheme. This weak dispersion is presumably mainly a consequence of the closure in moisture convergence of this scheme which does not leave many degrees of freedom for the parametrization over the ocean, where humidity is close to saturation, and the convergence of mass is strongly correlated to $\omega_{500}$. This correlation together with the absence of self inhibition explains the boundless linear increase of the heating rate as a function of $\omega_{500}$.

These features of the Tiedtke's scheme relate to commonly admitted statements about convective parametrizations. (i) A strong high frequency variability is often attributed to moisture convergence closures, whereas small high frequency variability seems to be a rather general feature of quasi-equilibrium massflux schemes (Horinouchi et al., 2003). Consistently, the high frequency variability of tropical rainfall is about 30 to $50 \%$ stronger with Tiedtke's than with Emanuel's scheme (not shown). In that respect, the TIEDTKE simulation is much closer to observations.

(ii) These features are also closely related to the waveCISK mechanism described by Lindzen (1974) by which coupling between convection and small spatial scale waves may lead to very localized strong convective events (grid points storms); the absence of evaporative cooling in Lindzen's model is worth mentioning here. (iii) Finally, these features probably explain the irrealistic patterns of strong rainfall obtained over oceans in the TIEDTKE simulation, over East Pacific (Fig. 11 and 12) all year round and over North-East of Madagascar in January (Fig. 11). Very similar pattern are indeed reported in climate simulations performed with the ECMWF model, although it uses a different closure for the Tiedtke's scheme which takes into account atmospheric stability (see e. g. Fig. 12 in Jakob and Siebesma, 2003). This apparent insensitivity to closure points to the key role of the lack of near surface cooling in Tiedtke's scheme over oceans.

In the much drier continental air over continents, both schemes yield a similar near surface cooling for precipitation rates smaller than $3-4 \mathrm{~mm} / \mathrm{d}$ (left panel in Fig. 19). For higher precipitation rates the cooling is bounded by $3 \mathrm{~K} / \mathrm{d}$ for Tiedtke's scheme while it reaches $6 \mathrm{~K} / \mathrm{d}$ with Emanuel's.

One can notice other differences between the two convection schemes. There is a thin layer of cooling around $100 \mathrm{hPa}$ with the Tiedtke's scheme which has no counterpart with the Emanuel's scheme (Fig. 14). The simulation with the Emanuel's scheme shows a systematic moistening between 250 and $150 \mathrm{hPa}$ which is predicted by Tiedtke's scheme on continents but not on oceans.

In the subsiding regimes over oceans, the near surface convective heating is positive in TIEDTKE and negative in the CONTROL simulation. Apart from this difference linked to the difference in rainfall evaporation, the heating rate profiles are qualitatively similar. They both exhibit a maximum heating of $1 \mathrm{~K} / \mathrm{d}$ around $900 \mathrm{hPa}$ and a small cooling between $800 \mathrm{hPa}$ and $550 \mathrm{hPa}$ (smaller with Emanuel's scheme).

The associated cloud covers are shown in Fig. 18. The fractional cover of mid-level clouds in convective regimes is much larger with Tiedtke's scheme, since the cloud cover is imposed as a constant between cloud basis and cloud top when convection is active. By comparison, the Emanuel's scheme coupled to the Bony and Emanuel (2001) cloud scheme produces less cloudiness below $500 \mathrm{hPa}$. In both simulations, there are very few boundary layer clouds in subsiding regimes over continents.

\section{Clouds}

Most of the changes observed in the large scale organisation of convection for CLOUDSA and B (Fig. 10) can be explained by looking at cloud radiative forcing in the regime-sorted framework (Fig. 20). 


\begin{tabular}{cccccccccc} 
& CRFNET & CRFLW & CRFSW & LWTOP & NETTOP & SWS & T2M & PRECIP & EVAP \\
\hline CONTROL & -5.3 & 51.5 & -56.7 & -237.0 & 70.9 & 225.1 & 25.6 & 5.3 & 4.2 \\
\hline & & \multicolumn{7}{c}{ Difference } & with CONTROL \\
\hline TIEDTKE & -13.4 & -6.8 & -6.7 & -8.6 & -14.8 & -9.5 & 0.6 & 1.4 & 0.6 \\
CLOUDSA & 7.5 & -4.4 & 11.9 & -4.5 & 6.7 & 12 & -0.1 & 0 & 0 \\
CLOUDSB & -3.5 & -18.8 & 15.2 & -24.6 & -9.7 & 15.1 & -0.4 & 0.6 & 0.4 \\
BUCKET & -1.4 & -2.1 & 0.5 & -1.8 & -2.1 & -0.4 & -0.1 & 0.2 & 0.1
\end{tabular}

Table 1: Net (CRFNET, $\mathrm{W} \mathrm{m}^{-2}$ ), longwave (CRFLW, $\mathrm{W} \mathrm{m}^{-2}$ ) and shortwave (CRFSW, $\mathrm{W} \mathrm{m}^{-2}$ ) cloud radiative forcing, infrared radiation to space (LWTOP, $\mathrm{W} \mathrm{m}^{-2}$ ), net radiation budget at the top of atmosphere (NETTOP,

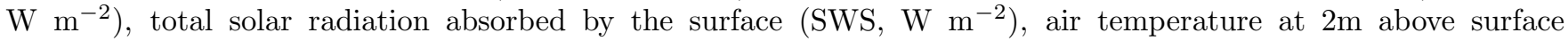
(T2M, Celcius), precipitation (PRECIP, $\mathrm{mm} \mathrm{d}^{-1}$ ) and evaporation (EVAP) averaged for convective regimes ($100 \mathrm{hPa} \mathrm{d} \mathrm{d}^{-1}<\omega_{500}<0$ ) over oceans between $30 \mathrm{~S}$ and $30 \mathrm{~N}$.

\begin{tabular}{cccccccccc} 
& CRFNET & CRFLW & CRFSW & LWTOP & NETTOP & SWS & T2M & PRECIP & EVAP \\
\hline CONTROL & 1.6 & 47.9 & -46.3 & -241.5 & 54.0 & 212.9 & 24.5 & 3.9 & 1.9 \\
\hline & & \multicolumn{7}{c}{ Difference } & with CONTROL \\
\hline TIEDTKE & -15.7 & -12.3 & -3.4 & -12.1 & -16.5 & -6.4 & -0.1 & -0.5 & -0.1 \\
CLOUDSA & 7.9 & 1 & 6.9 & 0.8 & 5.9 & 6 & 0.1 & 0.3 & 0.1 \\
CLOUDSB & -3.4 & -15.6 & 12.2 & -19.7 & -10.3 & 12 & -1.1 & 0 & 0.1 \\
BUCKET & -13.5 & -2.3 & -11.2 & 0 & -9 & -9.3 & -2 & 0.7 & 1.3
\end{tabular}

Table 2: Same as Table 1 but for continents.

The CONTROL simulation shows reasonable agreement with ERBE observations. In subsiding regimes $\left(\omega_{500}>0\right)$, the longwave, shortwave and net components of the cloud radiative forcings are reasonably close to the observation on average, when compared for instance to the previous generation of models (Bony et al., 2004). For the intermediate regimes, between -30 and $0 \mathrm{hPa} \mathrm{d}^{-1}$, the agreement is still good for the longwave radiative forcing but the shortwave forcing is not negative enough leading to a net negative forcing which is not strong enough. For strong convective regimes, between -90 and $-60 \mathrm{hPa} \mathrm{d}^{-1}$, the good agreement for the net forcing is due to a compensation of errors between the shortwave and longwave forcing.

The CLOUDSA experiment is very close to CONTROL in subsiding regimes (as expected). In convective regimes, the activation of the Bony and Emanuel (2001) cloud scheme (CONTROL versus CLOUDSA) reinforces the (negative) shortwave radiative forcing by about $10-15 \mathrm{~W} \mathrm{~m}^{-2}$, with almost no effect in the longwave. Because of the weaker shortwave radiative forcing $(<0)$ in CLOUDSA (with respect to CONTROL) more solar radiation can reach the surface. The mean solar radiation at the surface (SWS) is increased by 12 $\mathrm{W} \mathrm{m}{ }^{-2}$ on the averaged over the tropical oceans for convective regimes (Table 1) and by $6 \mathrm{~W} \mathrm{~m}^{-2}$ over continents (Table 2). This increased solar radiation increases the convection over continents but has almost no effect over ocean (SSTs are fixed) explaining the stronger minima of the velocity potential over Amazonia and Centre Africa (Fig. 9 and Fig. 10).

In CLOUDSB, the drier and less cloudy atmosphere (with respect to CONTROL) leads to a larger infrared cooling to space in the lower and mid troposphere. This increased cooling is only partly compensated by the weaker back-scattering of solar radiation by clouds. Over ocean with fixed SSTs, the larger cooling to space destabilizes the atmosphere and increases convection. This increased convection results in a colder nearsurface air over the ocean in convective regions (by $0.4 \mathrm{~K}$ on average, Table 1) despite the imposed SSTs. The same change in radiative forcing produces a cooling of continental surfaces (by about $1.1 \mathrm{~K}$ on average in the convective regimes, Table 2). This in turn explains the reduction of the large scale ascending motions reported in Fig. 10 and 11.

Similarly, the net radiative forcing is more negative in TIEDTKE simulation than in CONTROL in the convective regimes, which may also contribute to the reduction of large scale ascending motions over continents (Fig. 9, 11 and 12). 

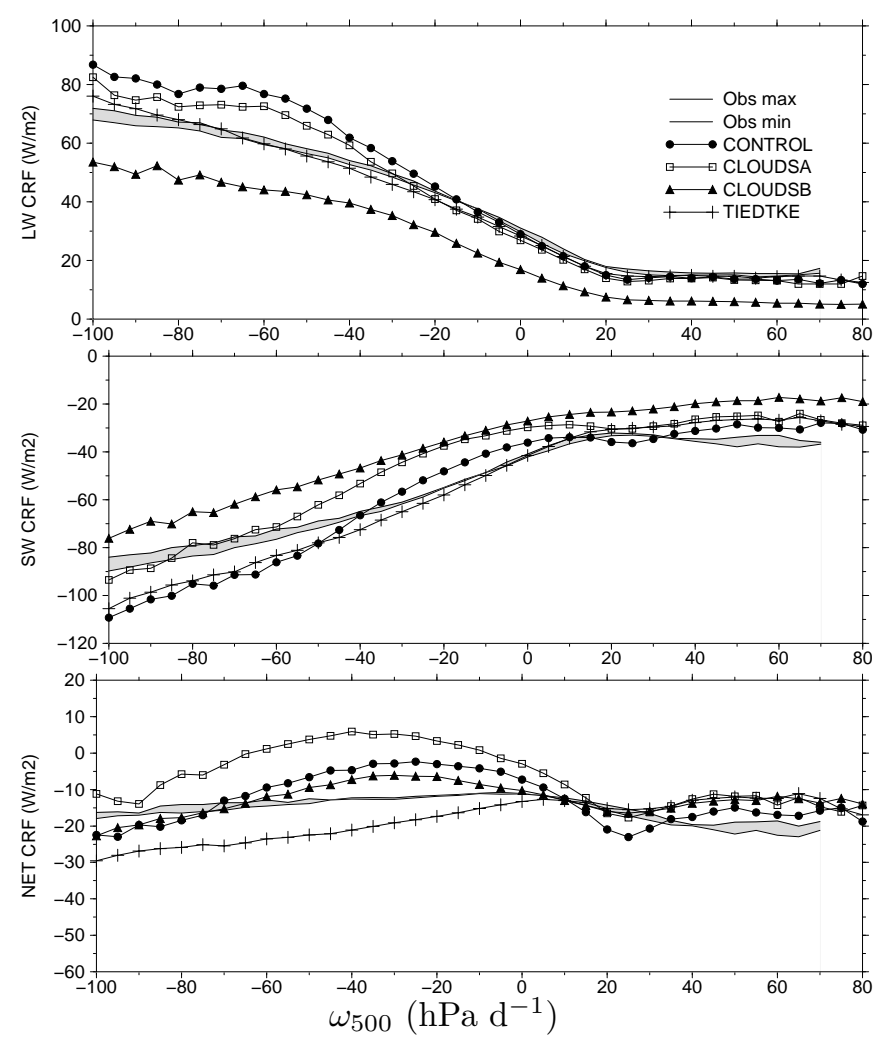

Figure 20: Cloud radiative forcing (CRF) in the 30S$30 \mathrm{~N}$ latitude band over ocean (top: long wave CRF; middle: short wave CRF; bottom: net CRF)

\section{Surface scheme}

We finally explain the weakening of large scale continental ascent in the BUCKET experiment (Fig. 11). The bucket model tends to evaporate much more easily convective rainfall over continental convective regions. The effect on temperature (cooling by more than $2 \mathrm{~K}$, Table 2) is probably dominant and explains the reduction in continental large scale convection. This effect is particularly clear in January over the Indian ocean as explained below. In July (not shown) the rainfall over India is even better represented with the bucket model in the sense that it extends farther north-west, toward Pakistan. This improvement is probably due to a local coupling: the rapid cooling of the surface by faster evaporation of convective rainfall (with respect to the CONTROL simulation) favours a triggering of convection in the very hot regions further north. The impact over African monsoon is however very weak. The same effect probably explains also the weaker rainfall over the largest islands in the oceanic continent in January, in better agreement with observations.

\section{Concluding remarks}

The development of the new version of the IPSL coupled model defines the new cycle, LMDZ4, of the LMD atmospheric general circulation model. The LMDZ4 model still exhibits significant biases. First, the mean thermal structure exhibits a cold bias of several K in mid and high latitudes at the tropopause. This bias is sensitive to the transport of water in that region, an increase in water reinforcing the infrared cooling to space there. A second important bias, attributable to the rather coarse horizontal resolution retained for the climate change simulations, is a systematic shift of the winter jets toward the equator. The model also tends to produce monsoon rainfalls that are spatially too confined. Part of the explanation comes from the coupling with the surface scheme as suggested by the better extension of the Indian monsoon toward Pakistan with the BUCKET scheme. The cloud radiative forcing still exhibits some biases but smaller than what was generally obtained in the previous generation of climate models (Bony et al., 2004).

Despite those biases, the LMDZ4 version represents a significant step further with respect to the previous LMDZ3 version (Li and Conil, 2003). When coupled to the ORCALIM oceanic model (Madec et al., 1998; Fichefet and Maqueda, 1997), it also reproduces a rather satisfactory seasonal cycle and interannual variability in the tropics (Marti et al., 2005).

A major improvement arises from the change of the parametrization of convection and clouds. With respect to the Tiedtke's scheme used in previous versions, the Emanuel's scheme improves the representation of the Hadley-Walker circulation, with a relatively stronger and deeper large scale ascent over continents, and suppress the irrealistic patterns of strong rainfall over tropical oceans. Thanks to the regime-sorted framework, originally proposed by Bony et al. (2004) to analyse the cloud radiative forcing and sensitivity, these differences were attributed to intrinsic differences in the vertical distribution of the convective heating and to the lack of self-inhibition by precipitating downdraughts for the Tiedtke's scheme. The combined use of velocity (or z-weighted) potential to characterize the large scale circulation on the one hand, and regime-sorted approach on the other, appears as a promising framework to work on the validation and improvement of the physical content of atmospheric general circulation models.

The parametrization of clouds has also a significant impact on the relative intensity of large scale convection over land and ocean. The coupling of the convection scheme with clouds according to Bony and Emanuel 
(2001) reinforces the backscattering of solar radiation by convective clouds, thus cooling and reducing the convection over continents. This continental convection is probably still a little bit too strong in the standard version when compared to ERA40 reanalysis.

The modifications of the large scale divergent circulation has very important implications for the coupling with the ocean. For instance, the erroneous maximum of precipitation observed on the Indian Ocean, north-east of Madagascar, in three of the sensitivity experiments (CLOUDSB, BUCKET and TIEDTKE) is associated with a strong underestimate of the eastward equatorial wind stress over the Indian Ocean (converging over Indonesia), or even with a stress in the wrong direction (toward the west). The Emanuel's and Tiedtke's versions of LMDZ4, which only differ in the treatment of the cumulus convection and associated clouds, have been used to further analyse the impact of the parametrized physics on the coupling with ocean and on the climate response to an increase of the concentration of greenhouse gases in the atmosphere. The results of those simulations will be analysed in a companion paper.

\section{Acknowledgements}

The numerical simulations presented here were performed on the NEC-SX5 of the IDRIS/CNRS computer centre. The graphics have been made with the user-friendly and public domain graphical package GrADS originally developed by Brian Dotty (COLA, support@grads.iges.org). The authors thank the anonymous referees for their constructive comments which helped us to improve the original version of the paper.

\section{References}

Arctic Climatology Project, Environmental working group arctic meteorology and climate atlas, CD-Rom, edited by Fetterer, F. and Radionov, V., National Snow and Ice Data Center, Boulder, CO, 2000.

Automatic Weather Stations Greenland Project, Greenland aws data, digital data available on http://amrc.ssec.wisc.edu/greenland.html, 2004.

Automatic Weather Stations Project, Archive aws data, digital data available on http://amrc.ssec.wisc.edu/aws.html, 2004.

Barkstrom, B. R., 1984, The earth radiation budget experiment (ERBE), Bull. Am. Meteorol. Soc., 65, 1170-1185, 1984.
Blackmon, M. L., 1976, A climatological study of the $500 \mathrm{mb}$ geopotential height of the northern hemisphere, J. Atmos. Sci., 33, 1607-1623, 1976.

Bony, S., and J.-L. Dufresne, 2005, Marine boundary layer clouds at the heart of cloud feedback uncertainties in climate models, Geophys. Res. Lett., 32, (20), L20806, doi: 10.1029/2005GL023851, 2005.

Bony, S., and K. A. Emanuel, 2001, A parameterization of the cloudiness associated with cumulus convection; evaluation using TOGA COARE data, J. Atmos. Sci., 58, 3158-3183, 2001.

Bony, S., K.-M. Lau, and Y. C. Sud, 1997, Sea surface temperature and large-scale circulation influences on tropical greenhouse effect and cloud radiative forcing., J. Clim., 10, 2055-2077, 1997.

Bony, S., J.-L. Dufresne, H. Le Treut, J.-J. Morcrette, and C. Senior, 2004, On dynamic and thermodynamic components of cloud changes, Climate Dynamics, 22, 71-86, 2004.

Boucher, O., and M. Pham, 2002, History of sulfate aerosol radiative forcings, Geophys. Res. Lett., 29, (9), 2002.

Braconnot, P., Tests de sensibilité, Note technique 0076, IPSL, http://www.ipsl.jussieu.fr/poles/ Modelisation/NotesTechniques.htm, 1998.

Chen, B., D. H. Bromwich, K. M. Hines, and X. Pan, 1995, Simulations of the 1979-1988 polar climates by global climate models, Ann. Glaciol., 21, 83-90, 1995.

Cosme, E., F. Hourdin, C. Genthon, and P. Martinerie, 2005, Origin of dimethylsulfide, non-seasalt sulfate, and methanesulfonic acid in eastern Antarctica, J. Geophys. Res., 110, D03302, doi:10.1029/2004JD004881, 2005.

de Rosnay, P., J. Polcher, M. Bruen, and K. Laval, 2002, Impact of a physically based soil water flow and soil-plant interaction representation for modeling large scale land surface processes, J. Geophys. Res., 10\%, 10.1029/2001JD000634, 2002.

Deardorff, J. W., 1966, The counter-gradient heatflux in the lower atmosphere and in the laboratory, J. Atmos. Sci., 23, 503-506, 1966.

Dufresne, J., and J. Grandpeix, Raccordement des modèles thermodynamiques de glace, d'océan et d'atmosphère, Note Interne 205, L.M.D., juin 1996. 
Dufresne, J.-L., J. Quaas, O. Boucher, F. Denvil, and L. Fairhead, 2005, Contrasts in the effects on climate of anthropogenic sulfate aerosols between the 20th and the 21st century, Geophys. Res. Lett., 32, L21703, doi: 10.1029/2005GL023619, 2005.

Emanuel, K. A., J. D. Neelin, and C. S. Bretherton, 1994, On large-scale circulations in convective atmospheres, Q. J. R. Meteorol. Soc., 120, 1111$1143,1994$.

Emanuel, K. A., 1991, A scheme for representing cumulus convection in large-scale models, J. Atmos. Sci., 48, 2313-2335, 1991.

Emanuel, K. A., 1993, A cumulus representation based on the episodic mixing model: the importance of mixing and microphysics in predicting humidity, A.M.S. Meteorol. Monographs, 24, (46), 185-192, 1993.

EPICA community members, 2004, Eight glacial cycles from an Antarctic ice core, Nature, 429, 623-628, 2004 .

ERA-40 by ECMWF, 2002, ERA-40, forty-year european re-analysis of the global atmosphere, 2002, http://www.ecmwf.int/products/data/archive/descript

Fichefet, T., and M. M. Maqueda, 1997, Sensitivity of a global sea ice model to the treatment of ice thermodynamics and dynamics, J. Geophys. Res., 102, 12,609-12,646, 1997.

Forget, F., F. Hourdin, R. Fournier, C. Hourdin, O. Talagrand, M. Collins, S. R. Lewis, P. L. Read, and J.-P. Huot., 1999, Improved general circulation models of the Martian atmosphere from the surface to above 80 km, J. Geophys. Res., 104, 24,155-24,176, 1999.

Fouquart, Y., and B. Bonnel, 1980, Computations of solar heating of the Earth's atmosphere: A new parametrization, Contrib. Atmos. Phys., 53, 35-62, 1980.

Gates, W. L., 1992, AMIP: The Atmospheric Model Intercomparison Project, Bull. of Am. Meteorol. Soc., 1992.

Genthon, C., G. Krinner, and E. Cosme, 2002, Free and laterally-nudged Antarctic climate of an Atmospheric General Circulation Model, Monthly Weather Rev., 130, 1601-1616, 2002.

Grandpeix, J.-Y., V. Phillips, and R. Tailleux, 2005, Improved mixing representation in emanuel's convection scheme, Q. J. R. Meteorol. Soc., in press, 2005 .

Gregory, J., R. Stouffer, S. Raper, P. Stott, and N. Rayner, 2005, An observationally based estimate of the climate sensitivity, J.of Clim., 15, (22), 31173121, 2005.

Grenier, H., H. Le Treut, and T. Fichefet, 2000, Ocean-atmosphere interactions and climate drift in a coupled general circulation model, Climate Dynamics, 16, 701-717, 2000.

Guichard, F., J. C. Petch, J.-L. Redelsperger, P. Bechtold, J.-P. Chaboureau, S. Cheinet, W. Grabowski, H. Grenier, C. G. Jones, M. Köhler, J.-M. Piriou, R. Tailleux, and M. Tomasini, 2004, Modelling the diurnal cycle of deep precipitating convection over land with cloud-resolving models and single-column models, Q. J. R. Meteorol. Soc., 130, (604C), 3139$3172,2004$.

Hauglustaine, D. A., F. Hourdin, L. Jourdain, M.A. Filiberti, S. Walters, J.-F. Lamarque, and E. A. Holland, 2004, Interactive chemistry in the Laboratoire de Météorologie Dynamique general circulation model: Description and background tipasdspatreric chemistry evaluation, J. Geophys. Res., 109, 4314-4357, 2004.

Heymsfield, A. J., and C. Platt, 1984, A parameterization of the particle size spectrum of ice clouds in terms of the ambient temperature and the ice water content, J. Atmos. Sci., 41, 846-855, 1984.

Horinouchi, T., S. Pawson, K. Shibata, U. Langematz, E. Manzini, M. A. Giorgetta, F. Sassi, R. J. Wilson, K. Hamilton, J. de Grandpré, and A. A. Scaife, 2003, Tropical Cumulus Convection and UpwardPropagating Waves in Middle-Atmospheric GCMs., J. Atmos. Sci., 60, 2765-2782, 2003.

Hosking, J. R. M., and J. R. Wallis, Regional frequency analysis: An approach based on Lmonents., Cambridge University Press, 224 pp, 1997.

Hoskins, B. J., H. H. Hsu, I. N. James, M. Masutani, P. D. Sardeshmuck, and G. H. White, Diagnostics of the global atmospheric circulation based on ecmwf analysis 1979-1989, Technical document, WCRP/WMO, 1996.

Hourdin, F., and A. Armengaud, 1999, The use of finite-volume methods for atmospheric advection of trace species. part i: Test of vairious formulations in a general circulation model, Mon. Wea. Rev., 127, 822-837, 1999. 
Hourdin, F., and J.-P. Issartel, 2000, Sub-surface nuclear tests monitoring through the CTBT xenon network, Geophys. Res. Lett., 27, 2245-2248, 2000.

Hourdin, F., P. Le Van, F. Forget, and O. Talagrand, 1993, Meteorological variability and the annual surface pressure cycle on Mars, J. Atmos. Sci., 50, 3625-3640, 1993.

Hourdin, F., O. Talagrand, R. Sadourny, C. Régis, D. Gautier, and C. P. McKay, 1995, General circulation of the atmosphere of Titan, Icarus, 11\%, 358-374, 1995.

Hourdin, F., S. Lebonnois, D. Luz, and P. Rannou, 2004, Titan's stratospheric composition driven by condensation and dynamics, J. Geophys. Res., 109, E12005, doi:10.1029/2004JE002282, 2004.

Hourdin, F., A. Idelkadi, and O. Talagrand, Eulerian backtracking of atmospheric tracers: II numerical aspects, QJRMS, in press, 2005.

Jacquart, C., and E. Choisnel, 1995, Un modèle de bilan hydrique simplifié à deux réservoirs utilisable en agrométéorologie, La Météorologie, 8, 4-17, 1995.

Jakob, C., and A. P. Siebesma, 2003, A new subcloud model for mass-flux convection schemes: Influence on triggering, updraft properties, and model climate, Mon. Wea. Rev., 131, 2765-2778, 2003.

James, I. N., 1989, The Antarctic drainage flow: implications for hemispheric flow on the Southern hemisphere, Antarctic Science, 1, 279-290, 1989.

Kasahara, A., Computational aspects of numerical models for weather prediction and climate simulation, in Methods in computational physics, edited by J. Chang, vol. 17, 1-66, Academic press, inc., 1977.

King, J., and W. Connolley, 1997, Validation of the surface energy balance over the antarctic ice sheets in the uk meteorological office unified climate model, J. Climate, 1273-1287, 1997.

Klein, S. A., and C. Jakob, 1999, Validation and sensitivities of frontal clouds simulated by the ECMWF model, Mon. Wea. Rev., 127, 2514-2531, 1999.

Krinner, G., and C. Genthon, 1998, GCM simulations of the Last Glacial Maximum surface climate of Greenland and Antarctica, Clim. Dyn., 14, 741-758, 1998.

Krinner, G., and C. Genthon, 1999, Altitude dependence of the surface climate over the ice sheets, Geophys. Res. Lett., 26, 2227-2230, 1999.
Krinner, G., and C. Genthon, 2003, Tropospheric transport of continental tracers towards Antarctica under varying climatic conditions, Tellus, 53, 54-70, 2003.

Krinner, G., C. Genthon, Z.-X. Li, and P. Le Van, 1997, Studies of the Antarctic climate with a stretchedgrid general circulation model, J. Geophys. Res., 102, 13731-13745, 1997.

Krinner, G., J. Mangerud, M. Jakobsson, M. Crucifix, C. Ritz, and J. Svendsen, 2004, Enhanced ice sheet growth in Eurasia owing to adjacent ice dammed lakes, Nature, 427, 429-432, 2004.

Krinner, G., N. Viovy, N. de Noblet-Ducoudré, J. Ogée, J. Polcher, P. Friedlingstein, P. Ciais, S. Sitch, and C. Prentice, 2005, A dynamic global vegetation model for studies of the coupled atmospherebiosphere system, Glob. Biogeochem. Cyc., 19, GB1015, 2005, doi:10.1029/2003GB002199.

Krinner, G., O. Magand, I. Simmonds, C. Genthon, and J. Dufresne, submitted, Simulated antarctic precipitation and surface mass balance of the end of the $20^{\text {th }}$ and $21^{\text {st }}$ centuries, Clim. Dyn., submitted.

Laval, K., R. Sadourny, and Y. Serafini, 1981, Land surface processes in a simplified general circulation model, Geophys. Astrophys. Fluid Dyn., 17, 129-150, 1981.

Le Treut, H., and Z. X. Li, 1991, Sensitivity of an atmospheric general circulation model to prescribed SST changes: Feedback effects associated with the simulation of cloud optical properties., Climate Dynamics, 5, 175-187, 1991.

Le Treut, H., Z. Li, and M. Forichon, 1994, Sensitivity study of the LMD GCM to greenhouse forcing associated with two different cloud water parametrizations, J. Clim, 7, 1827-1841, 1994.

Le Treut, H., M. Forichon, O. Boucher, and Z. Li, 1998, Sulfate Aerosol Indirect Effect and $\mathrm{CO}_{2}$ Greenhouse Forcing: EquilibriumResponse of the LMD GCM and Associated Cloud Feedbacks., Journal of Climate, 11, 1673-1684, 1998.

Levrard, B., F. Forget, F. Montmessin, and J. Laskar, 2004, Recent ice-rich deposits formed at high latitudes on Mars by sublimation of unstable equatorial ice during low obliquity, Nature, 431, 1072-1075, 2004.

Li, Z. X., and S. Conil, 2003, A 1000-year simulation with the IPSL ocean-atmosphere coupled model, Annals of Geophysics, 46(1), 39-46, 2003. 
Li, Z., 1999, Ensemble Atmospheric GCM Simulation of Climate Interannual Variability from 1979 to 1994., Journal of Climate, 12, 986-1001, 1999.

Lindzen, R., 1974, Wave-cisk in the tropics, J. Atmos. Sci., 31, 156-179, 1974.

Lott, F., and M. Miller, 1997, A new sub-grid scale orographic drag parametrization: its formulation and testing., Q. J. R. Meteorol. Soc., 123, 101-128, 1997.

Lott, F., P. LeVan, and F. Hourdin, 2005, The stratospheric version of LMDZ: Dynamical climatologies, Artic oscillation, and impact on the surface climate, 2005.

Lott, F., 1999, Alleviation of stationary biases in a $\mathrm{gcm}$ through a mountain drag parametrization scheme and a simple representation of mountain lift forces, Monthly Weather Rev., 127, 788-801, 1999.

Louis, J.-F., 1979, A parametric model of vertical eddy fluxes in the atmosphere., Boundary-layer Meteorol., 17, 187-202, 1979.

Madec, G., P. Delecluse, M. Imbard, and M. Lévy, OPA 8.1, ocean general circulation model reference manual, Notes du pôle de modélisation, n. 11, Institut Pierre-Simon Laplace (IPSL), Paris, France, 1998.

Marti, O., P. Braconnot, J. Bellier, R. Benshila, S. Bony, P. Brockmann, P. Cadule, A. Caubel, S. Denvil, J.-L. Dufresne, L. Fairhead, M.-A. Filiberti, M.-A. Foujols, T. Fichefet, P. Friedlingstein, J.-Y. Grandpeix, F. Hourdin, G. Krinner, C. Lévy, G. Madec, I. Musat, N. de Nolbet, J. Polcher, and C. Talandier, The new IPSL climate system model: IPSL-CM4, Technical note, IPSL, available at http://dods.ipsl.jussieu.fr/omamce/IPSLCM4/DocIP 2005.

Morcrette, J. J., L. Smith, and Y. Fouquart, 1986, Pressure and temperature dependence of the absorption in longwave radiation parametrizations, Contrib. Atmos. Phys., 59, (4), 455-469, 1986.

Myneni, R., S. Hoffman, J. Glassy, Y. Zhang, P. Votava, R. Nemani, S. Running, and J. Privette, 2002, Global products of vegetation leaf area and fraction absorbed PAR from year one of MODIS data, Remote Sensing of Environment, 83, 214-231, 2002.

Poutou, E., G. Krinner, C. Genthon, and N. de NobletDucoudré, 2004, Impact of soil freezing on future boreal climate change, Clim. Dyn., 23, 621-639, 2004.
Quaas, J., O. Boucher, and F.-M. Bréon, 2004, Aerosol indirect effects in POLDER satellite data and the Laboratoire de Météorologie Dynamique-Zoom (LMDZ) general circulation model, J. Geophys. Res., 109, 2004.

Quadrelli, R., and J. M. Wallace, 2004, A simplified linear framework for interpreting patterns of northern hemisphere wintertime climate variability, J. Climate, 17, 3728-3744, 2004.

Rannou, P., F. Hourdin, and C. P. McKay, 2002, A wind origin for Titan's haze structure, Nature, 418 , 853-856, 2002.

Rossow, W. B., and R. A. Schiffer, 1999, Advances in understanding clouds from isccp, Bull. Amer. Meteor. Soc., 80, 2261-2287, 1999.

Sadourny, R., and K. Laval, January and July performance of the LMD general circulation model, in New perspectives in Climate Modeling, edited by A. Berger and C. Nicolis, Elsevier, 173-197, Amsterdam, 1984.

Sadourny, R., 1975 a, Compressible model flows on the sphere, J. Atmos. Sci., 32, 2103-2110, 1975 a.

Sadourny, R., 1975b, The dynamics of finite-difference models of the shallow-water equations, J. Atmos. Sci., 32, 680-689, 1975 b.

Sawyer, J. S., 1976, Observational characteristics of atmospheric fluctuations with a time scale of a month, Q. J. R. Meteorol. Soc., 96, 610-625, 1976.

Shuman, C., R. Alley, S. Anandakrishnan, J. White, P. Grootes, and C. Stearns, 1995, Temperature and accumulation at the Greenland Summit: Comparison $4 \varphi$, high-resolution isotope profiles and satellite passive microwave brightness temperature trends, $J$. Geophys. Res., 100, 9165-9177, 1995.

Slingo, J. M., 1987, The development and verification of a cloud prediction scheme for the ecmwf model, Q. J. R. Meteorol. Soc., 113, (477), 899-927, 1987.

Smith, S. D., 1988, Coefficients for sea surface wind stress, heat flux, and wind profiles as a function of wind speed and temperature, J. Geophys. Res., 93, 15467-15472, 1988.

Sommeria, G., and J. W. Deardorff, 1977, Subgrid-scale condensation in models of nonprecipitating clouds, J. Atmos. Sci., 34, 344-355, 1977. 
Suzuki, T., M. Tanaka, and T. Nakajima, 1993, The microphysical feedback of cirrus cloud in climatechange, J. Meteor. Soc. Japan, 71, (6), 701-714, 1993.

Taylor, K. E., D. Williamson, and F. Zwiers, The sea surface temperature and sea-ice concentration boundary conditions for AMIP II simulations, PCMDI Report No. 60 60, P.C.M.D.I., 2000.

Thompson, D. W. J., and J. M. Wallace, 1998, The Arctic Oscillation signature in the wintertime geopotential height and temperature fields, Geophys. Res. Lett., 25, 1297-1300, 1998.

Tiedtke, M., 1989, A comprehensive mass flux scheme for cumulus parameterization in large-scale models, Mon. Wea. Rev., 117, 1179-1800, 1989.

Van Leer, B., 1977, Towards the ultimate conservative difference scheme : IV. a new approach to numerical convection, J. Computational Phys., 23, 276-299, 1977.

Vaughan, D. G.and Bamber, J., M. Giovinetto, J. Russel, and A. Cooper, 1999, Reassessment of net surface mass balance in Antarctica, J. Climate, 12, 933-946, 1999.

Webb, M., C. Senior, S. Bony, and J.-J. Morcrette, 2001, Combining ERBE and ISCCP data to assess clouds in the Hadley Centre, ECMWF and LMD atmospheric climate models, Climate Dyn., 17, 905$922,2001$.

Wigley, T., P. Jones, and S. Raper, 1997, The observed global warming record: What does it tell us?, Pro. Nat. Acad. Sci., 94, (16), 8314-8320, 1997.

Wyant, M. C., C. S. Bretherton, J. T. Bacmeister, J. T. Kiehl, I. M. Held, M. Z. Zhao, S. A. Klein, and B. J. Soden, 2005, A comparison of tropical cloud properties and responses in gcms using midtropospheric vertical velocity, Climate Dyn., 2005, submitted.

Xie, P., and P. A. Arkin, 1997, A 17-year monthly analysis, based on gauge observations, satellite estimates, and, numerical model outputs, Bull. Am. Meteorol. Soc., 78, 2539-2558, 1997.

Zhang, M. H., W. Y. Lin, S. A. Klein, J. T. Bacmeister, S. Bony, R. T. Cderwall, A. D. Del Genio, J. J. Hack, N. G. Loeb, U. Lohmann, P. Minnis, I. Musat, R. Pincus, P. Stier, M. J. Suarez, M. J. Webb, J. B. Wu, M.-S. Xie, and J. H. Zhang, 2005, Comparing clouds and their seasonal variations in 10 atmospheric general circulation models with satellite measurements, J. Geophys. Res., 110, D15S02, doi:10.1029/2004JD005021, 2005.

Zhou, T. J., and Z. X. Li, 2002, Simulation of the east asian summer monsoon using a variable resolution atmospheric gcm, Clim. Dyn., 19, 167-180, 2002.

\section{A About verticaly integrated ve- locity potential}

The purpose of this appendix is: (i) to express the vertical momentum of atmospheric columns as a $\mathrm{z}$ weighted integral of the Laplacian of the velocity potential; (ii) to show that it is also approximately the Laplacian of a z-wheighted integral of the velocity potential. Only monthly mean velocity fields are considered and the scalar velocity potential at each level is chosen so that it is zero at the poles.

\section{A.1 Vertical momentum}

The vertical momentum $\tilde{w}$ of atmospheric columns reads:

$$
\tilde{w}=\int_{z_{s}}^{\infty} d z \rho w=-\int_{z_{s}}^{\infty} d z \frac{\omega}{g}
$$

where $w$ and $\omega$ are the vertical velocity expressed in $z$ and pressure coordinates, respectively and $z_{s}$ is the altitude of the surface.

Vertical integration of the continuity equation (taking into account $\vec{\nabla} \vec{V}=\nabla^{2} \varphi$ ) yields an expression of $\omega$ in terms of the velocity potential:

$$
\omega_{(z)}-\omega_{s}=\int_{z_{s}}^{z} d z^{\prime} \nabla^{2} \varphi_{\left(z^{\prime}\right)} \rho_{\left(z^{\prime}\right)} g
$$

For monthly mean fields, the term $\omega_{s}=\frac{\partial p_{s}}{\partial t}$ is negligible. Then, substitution of (8) in (7) yields:

$$
\tilde{w}=-\int_{0}^{\infty} d z \int_{z_{s}}^{z} d z^{\prime} \rho_{\left(z^{\prime}\right)} \nabla^{2} \varphi_{\left(z^{\prime}\right)}
$$

Let $Z_{0}$ be an altitude high enough so that $\omega_{\left(Z_{0}\right)} \simeq 0$. Then the integration may be limited to the triangle $\left(z<Z_{0}, z^{\prime}<z\right)$. Permuting the two integrations yields:

$$
\begin{aligned}
\tilde{w} & =-\int_{z_{s}}^{Z_{0}} d z^{\prime} \int_{z^{\prime}}^{Z_{0}} d z \rho_{\left(z^{\prime}\right)} \nabla^{2} \varphi_{\left(z^{\prime}\right)} \\
& =-\int_{z_{s}}^{Z_{0}} d z^{\prime} \rho_{\left(z^{\prime}\right)} \nabla^{2} \varphi_{\left(z^{\prime}\right)}\left(Z_{0}-z^{\prime}\right)
\end{aligned}
$$


The $Z_{0}$ term drops out since the vertical integral of $\nabla^{2} \varphi$ is close to zero:

$$
\tilde{w}=\frac{1}{g} \int_{p_{0}}^{p_{s}} d p z_{(p)} \nabla^{2} \varphi_{(p)}
$$

\section{A.2 Expressing the vertical momentum $\tilde{w}$ in terms of the potential of the geopotential transport}

We wish to express $\tilde{w}$ as the Laplacian of some potential. In order to do this, one has to commute the Laplacian operator in formula (10) with the $z$ term and with the integral operator.

We shall limit ourselves to the tropical band where the geopotential altitude has weak horizontal variations. With such an approximation, the Laplacian and the $z$ term commute.

Now we want to commute the horizontal differentials with the vertical integration. Taking into account the fact that the velocity is zero at the surface (so that $\vec{\nabla} \varphi\left(p_{s}\right)=0$ ), one may write:

$$
\begin{aligned}
\frac{\partial}{\partial x}\left(\int_{p_{0}}^{p_{s}} d p z \varphi\right) & =\int_{p_{0}}^{p_{s}} d p z \frac{\partial \varphi}{\partial x}+z_{\left(p_{s}\right)} \varphi_{\left(p_{s}\right)} \frac{\partial p_{s}}{\partial x} \\
\frac{\partial^{2}}{\partial x^{2}}\left(\int_{p_{0}}^{p_{s}} d p z \varphi\right) & =\int_{p_{0}}^{p_{s}} d p z \frac{\partial^{2} \varphi}{\partial x^{2}}+z_{\left(p_{s}\right)} \varphi_{\left(p_{s}\right)} \frac{\partial^{2} p_{s}}{\partial x^{2}}
\end{aligned}
$$

Adding the analog formula for the $y$ derivative, one gets:

$$
\nabla^{2}\left(\int_{p_{0}}^{p_{s}} d p z \varphi\right)=\int_{p_{0}}^{p_{s}} d p z \nabla^{2} \varphi+z_{\left(p_{s}\right)} \varphi_{\left(p_{s}\right)} \nabla^{2} p_{s}
$$

Over oceans, the last rhs term is zero. Over continents, it is not necessarily zero, because of orography. However, with a spatial resolution of the order of $100 \mathrm{~km}$, it stays several order of magnitude smaller than the first rhs term and we shall neglect it.

Then, one may write the vertical momentum $\tilde{w}$ as the Laplacian of a function $\tilde{\varphi}$ :

$$
\left\{\begin{array}{l}
\tilde{w} \simeq \frac{1}{g} \nabla^{2} \tilde{\varphi} \\
\tilde{\varphi}=\int_{p_{0}}^{p_{s}} d p z \varphi
\end{array}\right.
$$

Finally, using the same technique and the same approximations one may prove that $\tilde{\varphi}$ is close to the saclar potential of the horizontal transport $\vec{G}$ of
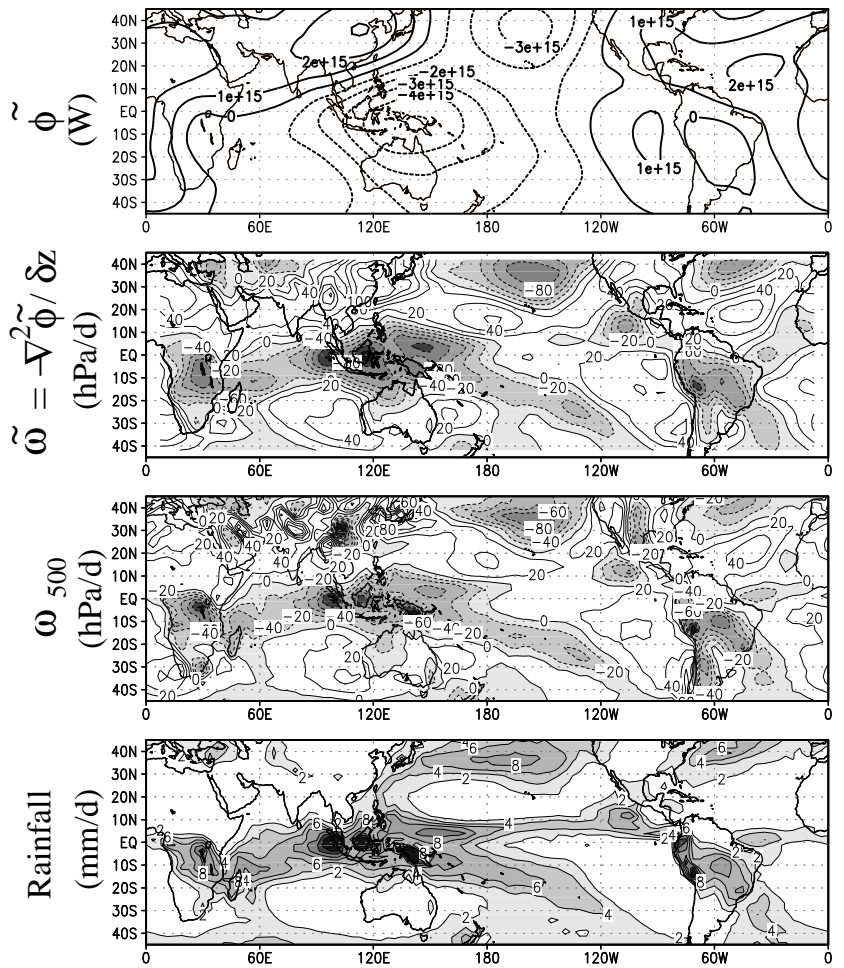

Figure 21: Potential $\tilde{\varphi}$ of the annual mean of the horizontal transport of geopotential (upper pannel) and mean vertical velocity $\quad \bar{\omega}=\frac{1}{Z_{0}-z_{s}} \int_{z_{0}}^{Z_{0}} d z \omega=\frac{-1}{Z_{0}-z_{s}} \nabla^{2} \tilde{\varphi} \quad$ (with $Z_{0}-z_{s}=15 \mathrm{~km}$ ) (second pannel) for one of the AMIP simulations; to be compared with $\omega_{500}$ and annual precipitation (two lower pannels).

geopotential:

$$
\begin{aligned}
\vec{G} & =\int_{0}^{\infty} d z \rho \vec{V} g z \\
& =\int_{0}^{p_{s}} d p z \vec{V}
\end{aligned}
$$

As an illustration, Fig. 21 displays the potential $\tilde{\varphi}$ of the annual mean geopotential transport and the mean vertical velocity. The similarity of $\bar{\omega}$ and $\omega_{500}$ is obvious. However, $\bar{\omega}$ is smoother than $\omega_{500}$ and might be a better indicator of dynamic regimes. Finally, the lowest pannel illustrates the strong link between large scale ascent and precipitation. 